\title{
Natural Killer Cell Functional Dichotomy in Chronic Hepatitis B and Chronic Hepatitis C Virus Infections
}

\author{
BARBARA OLIVIERO, ${ }^{*}$ STEFANIA VARCHETTA, ${ }^{*}$ ENRICA PAUDICE, ${ }^{*}$ GIUSEPPE MICHELONE, ${ }^{\ddagger}$ MARCO ZARAMELLA, ${ }^{\neq}$ \\ DOMENICO MAVILIO, ${ }^{\S}$ FRANCESCA DE FILIPPI," SAVINO BRUNO," and MARIO U. MONDELLI* \\ ${ }^{*}$ Research Laboratories and ₹Division of Infectious Diseases, Department of Infectious Diseases, Fondazione I.R.C.C.S. Policlinico San Matteo and University of Pavia, \\ Pavia; `Laboratory of Clinical and Experimental Immunology, I.R.C.C.S. Istituto Clinico Humanitas, Rozzano; and "Liver Unit, Department of Medicine, Azienda \\ Ospedaliera Fatebenefratelli e Oftalmico, Milan, Italy
}

BACKGROUND \& AIMS: The phenotypic and functional characteristics of natural killer (NK) cells in chronic hepatitis $\mathrm{B}$ virus (HBV) and hepatitis $\mathrm{C}$ virus (HCV) infections are incompletely defined and largely controversial. METHODS: We studied NK cell receptor expression, cytotoxic activity, and cytokine production in peripheral blood mononuclear cells from 35 patients with chronic hepatitis C, 22 with chronic hepatitis B, and 30 healthy controls. RESULTS: Patients with chronic $\mathrm{HBV}$ infection had an increased proportion of $\mathrm{NKG}_{2} \mathrm{C}^{+}$ NK cells with normal inhibitory receptor expression and a lower proportion of activated NK cells compared with $\mathrm{HCV}^{+}$patients, which was associated with normal or reduced cytolytic activity and markedly dysfunctional tumor necrosis factor- $\alpha$ and interferon- $\gamma$ production. Patients with chronic HCV infection showed a predominantly activating phenotype, featuring a decreased percentage of cells expressing the inhibitory receptor KIR3DL1 and a concomitant increase in the proportion of $\mathrm{NKG}_{2}{ }^{+} \mathrm{NK}$ cells. Expression of the CD69 early activation antigen on NK cells positively correlated with serum alanine aminotransferase and HCV RNA values, suggesting participation of virus-induced effector NK cells in liver necroinflammation. Phenotypic changes in $\mathrm{HCV}^{+}$ patients were associated with enhanced cytokine-induced cytolytic activity and increased usage of natural cytotoxicity and NKG2D receptor pathways, accompanied by defective cytokine production, although to a lesser extent than patients with chronic HBV infection. CONCLUSIONS: These findings provide evidence for a functional dichotomy in patients with chronic $\mathrm{HBV}$ and HCV infections, featuring conserved or enhanced cytolytic activity and dysfunctional cytokine production, which may contribute to virus persistence.

tudies on early immune defense mechanisms showed $\checkmark$ that hepatitis B virus (HBV) infection does not induce appreciable changes in innate immune response genes in the first weeks of infection, whereas hepatitis $\mathrm{C}$ virus (HCV) efficiently induces interferon (IFN) $\alpha / \beta$ response genes. ${ }^{1}$ However, available evidence suggests that HCV eludes innate cellular defense mechanisms by blocking IFN-signaling pathways. $^{2-5}$ Interestingly, despite the apparent silence of $\operatorname{IFN} \alpha / \beta$ response genes in HBV-infected chimpanzees, there is evidence of natural killer $\mathrm{T}$ (NKT) cell activation in the transgenic mouse model of HBV infection, which can inhibit virus replication via IFN- $\gamma$ production, ${ }^{6}$ and, in addition, NKT cells can be triggered during HBV infection by the expression of stress signals on infected hepatocytes recognized by natural killer cell receptors (NKRs). ${ }^{7}$

NK cells are important antiviral effectors of innate immunity because of their contribution to virus elimination via direct killing of infected cells and cytokine (IFN- $\gamma$ and tumor necrosis factor [TNF]- $\alpha$ ) production, and their regulation depends on a fine balance between inhibitory and activating receptors (NKRs). ${ }^{8-10}$ Preferential expression of the inhibitory receptor KIR2DL3 on NK cells has been reported in patients with a self-limited outcome of acute HCV infection acquired by a low-dose exposure. ${ }^{11}$ However, the real impact of these mechanisms on NK cell function is unknown because phenotypic changes do not necessarily reflect altered function. ${ }^{12,13}$ The observations that the interaction of the E2 protein of $\mathrm{HCV}$ with CD81 on NK cells inhibits their activation ${ }^{14,15}$ and that NK cell functions can be deficient in individuals chronically infected with HCV ${ }^{16-29}$ suggest that HCV may actually contribute to impair the NK cell response, although the data are still controversial. ${ }^{20}$

In the present study, we have performed an extended phenotypic analysis of peripheral blood NK cells in chronic HBV and HCV infections by determining activating and inhibitory NKR expression. In addition, we examined NK cytolytic potential and cytokine production in the presence or absence of cytokine stimulation. We

\footnotetext{
Abbreviations used in this paper: $\mathrm{HBV}$, hepatitis B virus; HCV, hepatitis $\mathrm{C}$ virus; ICS, intracellular staining; IFN- $\gamma$, interferon $\gamma$; mAbs, monoclonal antibodies; MICA-B, major histocompatibility complex class I-chain related proteins $A$ and $B$; NCR, natural cytotoxicity receptor; NK, natural killer; NKR, natural killer receptor; NKT, natural killer T; PBMC, peripheral blood mononuclear cells; RAE-1, retinoic acid early inducible protein 1; TNF- $\alpha$, tumour necrosis factor $\alpha$.

(1) 2009 by the AGA Institute 0016-5085/09/\$36.00 doi:10.1053/j.gastro.2009.05.047
} 
show that NK cells from patients with chronic HBV and chronic HCV infections differ in NKR expression and that NK function is characterized by a conserved or enhanced cytolytic activity and a dysfunctional cytokine production. This defect may be an important mechanism contributing to virus persistence.

\section{Materials and Methods}

\section{Isolation and Storage of Peripheral Blood Mononuclear Cells}

Twenty milliliters of venous blood was drawn from 35 consecutive untreated patients with chronic HCV infection, 22 with chronic HBV infection, and 30 healthy donors. Informed consent in writing was obtained from each individual. The study protocol conformed to the ethical guidelines of the 1975 Declaration of Helsinki and was approved by the Institutional Review Board and Ethical Committee of Fondazione I.R.C.C.S. Policlinico San Matteo. The characteristics of HBV-positive and HCV-positive patients are listed as Supplementary Table 1. Peripheral blood mononuclear cells (PBMC) were isolated by standard Ficoll-Isopaque density gradient centrifugation (Lympho Separation Medium, MP Biomedicals, $\mathrm{OH}$ ) and stored in liquid nitrogen.

\section{Cell Surface Staining and Flow Cytometry Analysis}

NKR phenotype was carried out as previously described. ${ }^{21}$ NK cells were identified in PBMC as $\mathrm{CD}^{-}$/ $\mathrm{CD} 20^{-} / \mathrm{CD}^{2} 6^{+}$and could be easily defined as $\mathrm{CD} 56^{\mathrm{dim}}$ and $\mathrm{CD} 56^{\text {bright }}$ according to fluorescence intensity. Expression of several activating (NKG2D, CD94/NKG2C, NKp44, NKp46, and NKp30) and inhibitory (IRP60, CD94/NKG2A, KIR2DL1, KIR2DL2, KIR3DL1, LIR1/ ILT2, p75/AIRM1) NKRs, as well as coreceptors (2B4, NTB-A, NKp80, DNAM.1) and early activation molecules (CD69) was examined by labelling with monoclonal antibodies (mAbs) as described previously. ${ }^{21}$ In addition, a detailed analysis of single inhibitory receptor expression was carried out using PE-conjugated IgG1 mAbs specific for KIR2DL2/DL3/DS2 (CD158 b1,b2,j), KIR2DL1/DS1 (CD158 a,h), KIR3DL1/DS1 (Z27, CD158 e1,e2), and ILT2 (CD85), all from Beckman Coulter, Fullerton, CA. Flow cytometry analysis was performed using a 2 laser FACSCalibur instrument equipped with CellQuest Pro software (BD Bioscience).

\section{Cytokine Production by Intracellular Staining}

Intracellular staining (ICS) was carried out as described elsewhere, ${ }^{22}$ with minor modifications. TNF- $\alpha$ and IFN- $\gamma$ production by NK cells was tested by ICS after overnight stimulation of PBMC with different combinations of cytokines: interleukin (IL)-2 $(100 \mathrm{U} / \mathrm{mL}$; Biosource, Camarillo, CA) + IL-12 (0.5 ng/mL; R\&D System, Minneapolis, MN) and IL-2 (100 U/mL) + IL-21 (100 $\mathrm{ng} / \mathrm{mL}$; Biosource). IL-21 was used in cytokine combina- tions because it was shown to efficiently stimulate IFN- $\gamma$ production by NK cells ${ }^{23,24}$ and was as effective or more than IL-15 in stimulating CD107a degranulation and cytokine production as shown by preliminary experiments (Supplementary Figure $1 A-D$ ). After stimulation, PBMCs were plated at $2 \times 10^{5}$ cells/well with GolgiStop solution (BD Biosciences, San Jose, CA) in 96 well flat bottom plates coated with $10 \mu \mathrm{g} / \mathrm{mL}$ anti-CD16 (Fc $\gamma \mathrm{RIII})$ IgM antibody (Immunological Sciences, Rome, Italy). CD16 engagement on CD56 $6^{\text {bright }}$ cells is a secondary signal required for IFN- $\gamma$ production, ${ }^{25}$ and CD16 expression on these cells was shown to increase 3- to 4-fold following stimulation with the cytokine combinations employed in this study (Supplementary Figure 2). Unstimulated PBMCs and uncoated plates served as negative controls. After 4-hour incubation at $37^{\circ} \mathrm{C}$, cells were harvested, washed with phosphate-buffered saline (PBS) 2\% fetal bovin serum (FBS), and stained for 30 minutes at $4{ }^{\circ} \mathrm{C}$ with directly conjugated antiCD56 PC5, anti-CD19 PE, and anti-CD3 FITC antibodies. Next, PBMCs were washed, fixed, and permeabilized by BD Cytofix/Cytoperm Solution (BD Biosciences) according to the manufacturer's instructions and stained with antiIFN- $\gamma$ or anti-TNF- $\alpha$ allophycocyanin (APC)-conjugated antibodies (BD Biosciences).

\section{CD107a Degranulation Assay}

CD107a degranulation assay was performed as described, ${ }^{26}$ with minor modifications. Although CD107a degranulation is an indirect measure of cytotoxicity, it is now widely used to assess the cytotoxic potential of $\mathrm{CD}^{+} \mathrm{T}$ cells and NK cells, ${ }^{27}$ and it has been shown that there is a linear correlation between data obtained with the traditional ${ }^{51} \mathrm{Cr}$ release assay and the $\mathrm{CD} 107 \mathrm{a}$ degranulation assay. ${ }^{28}$ Briefly, after a 72-hour stimulation with different combinations of cytokines (IL-2+ IL-12 and IL-2+IL-21), PBMCs were washed and incubated for 3 hours at $37^{\circ} \mathrm{C}$ with $\mathrm{K} 562$ or P815 target cells $(\mathrm{E}: \mathrm{T}=1: 1)$ in the presence of anti-CD107a PE antibody. Lytic activity was determined by flow cytometry and expressed as percentage of $\mathrm{CD} 107 \mathrm{a}^{+} / \mathrm{CD} 6^{+} / \mathrm{CD}^{-} \mathrm{NK}$. Moreover, redirected cytotoxicity experiments were set up in which PBMCs were cultured with $\mathrm{Fc} \gamma \mathrm{R}^{+} \mathrm{P} 815$ target cells, with or without $\mathrm{mAb}$ specific for the natural cytotoxicity receptors (NCRs) NKp30 and NKp46 and for NKG2D. ${ }^{29}$ The latter approach allows binding of the $\mathrm{mAb}$ to P815 target cells via the immunoglobulin Fcy receptor and at the same time triggering of the lytic process through binding to the activating receptor expressed on effector cells. As for ICS, IL-21 was used in cytokine combinations because it was shown to augment NK cell proliferation and cytolytic activity. ${ }^{23,24}$ Original data illustrating positive and negative controls of the CD107a degranulation assay are included as Supplementary Figure 3. 


\section{Statistical Analysis}

The nonparametric Mann-Whitney $U$ test was used to compare data, which were not normally distributed, between the different groups. Phenotypic and functional data are expressed as median percentage, $95 \%$ confidence interval (CI). Correlations between variables were analyzed using the Pearson correlation coefficient $(r)$. A $P$ value $\leq .05$ was deemed statistically significant.

\section{Results}

\section{Peripheral Blood NK Cell Subsets in Patients With Chronic HBV and HCV Infections}

The proportion of circulating NK cells was significantly lower in $\mathrm{HCV}^{+}$and $\mathrm{HBV}^{+}$patients compared with healthy subjects (Figure 1A). The frequency of NK cells expressing the NKG2C activating receptor was significantly higher in HBV-positive patients compared with $\mathrm{HCV}^{+}$patients and healthy subjects (Figure $1 B$ ), whereas the frequency of NK cells expressing the NKG2D activating receptor was significantly increased in $\mathrm{HCV}^{+}$patients compared with healthy controls (Figure 1C). Dot plots reporting staining with NKG2D-specific $\mathrm{mAb}$ and an isotype control in representative subjects are shown as Supplementary Figure 4. The frequency of $\mathrm{CD} 69^{+}$-activated NK cells was higher in $\mathrm{HCV}^{+}$patients compared with $\mathrm{HBV}^{+}$patients $(P=.044)$, even though both patient groups failed to show statistically significant differences with healthy subjects (Figure 1D). The observations showing increased proportions of NK cells expressing activation markers were supported by data on mean fluorescence intensity per cell, which was also increased (Supplementary Figure $5 A-C$ ). Conversely, the proportion of NK cells expressing inhibitory receptors (INKRs), identified by a pool of monoclonal antibodies directed against KIR2DL1, KIR2DL2, KIR3DL1, and LIR1/ILT2, was significantly reduced in $\mathrm{HCV}^{+}$but not in $\mathrm{HBV}^{+}$ patients compared with controls (Figure $1 E$ ). To identify which of the inhibitory receptor(s) was expressed at a lower level in patients with chronic HCV infection, we studied 17 patients with chronic HBV infection, 21 with chronic HCV infection, and 20 healthy donors, using single-receptor specific mAbs as detailed above. There was a statistically significant decrease in the proportion of KIR3DL1/DS1-expressing NK cells both in HCV- and HBV-infected patients (Figure 2A). However, when the activating KIR3DS1 allele-expressing NK cells (defined as the dim fraction of CD158 e1,e2 positive cells identified by $\mathrm{mAb} Z 27$, Figure $2 B$ ) were subtracted from analysis, the reduction remained significant in HCV-infected patients only (Figure 2C). Expression of the other inhibitory
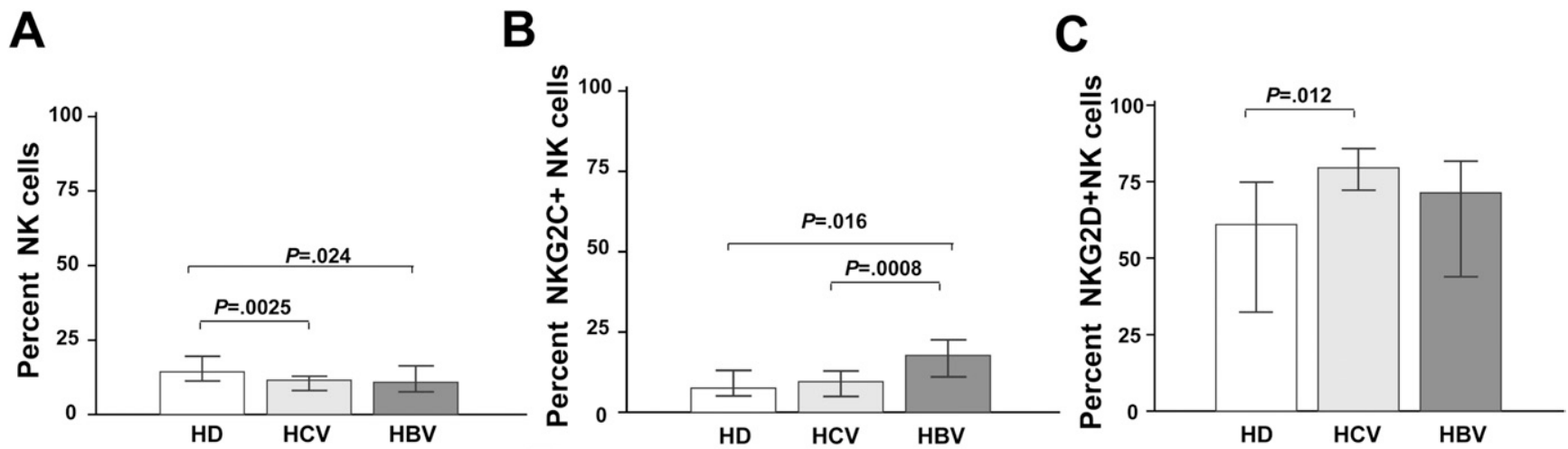

D
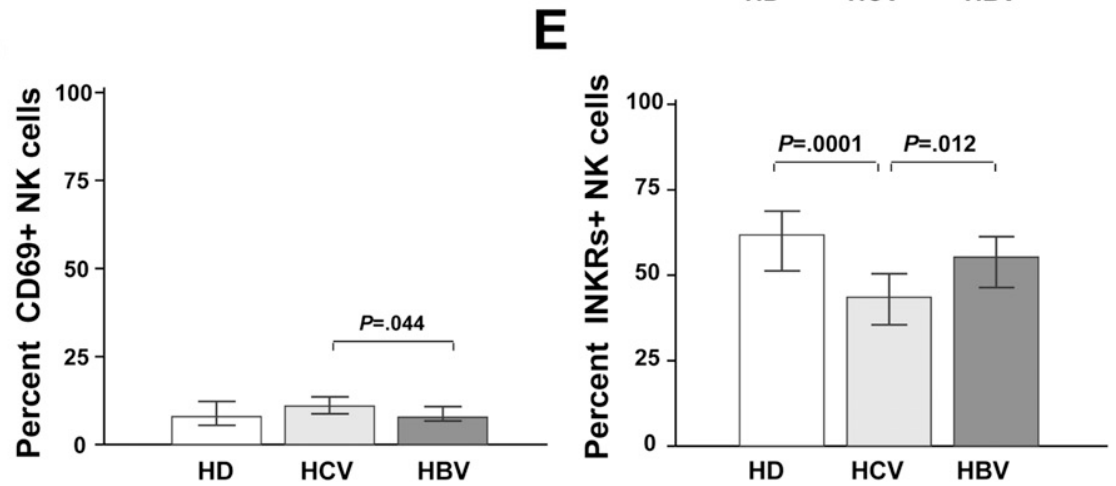

Figure 1. Frequencies and phenotype of circulating $\mathrm{NK}$ cells are significantly reduced in both $\mathrm{HCV}^{+}$and $\mathrm{HBV}^{+}$patients compared with healthy donors $(A)$. Increased proportion of $\mathrm{NKG}_{2} \mathrm{C}^{+} \mathrm{NK}$ cells in $\mathrm{HBV}^{+}$patients $(B)$, and of NKG2D+ $\mathrm{NK}^{+}$cells in $\mathrm{HCV}^{+}$patients $(C)$, compared to HD. The proportion of activated $\left(\mathrm{CD}{ }^{+}\right) \mathrm{NK}$ cells is higher in $\mathrm{HCV}^{+}$patients compared with $\mathrm{HBV}^{+}$patients but not significantly so compared with healthy donors $(D)$. Reduced proportion of NK cells expressing a broad range of inhibitory receptors (INKRs) identified by a pool of mAbs (E). HD, healthy controls (empty bars); HCV, patients with chronic HCV infection (solid light grey bars); HBV, patients with chronic HBV infection (solid dark grey bars). 


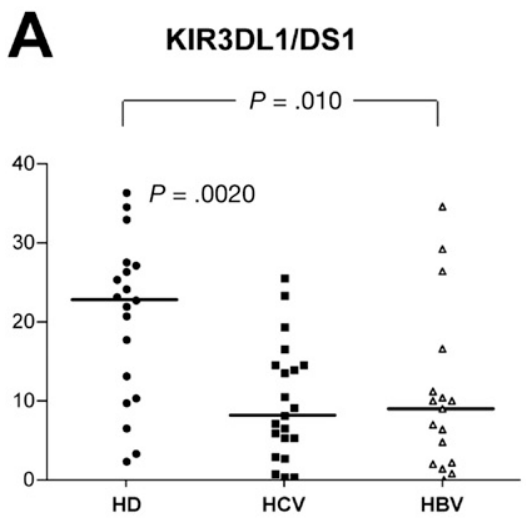

KIR2DL1/DS1

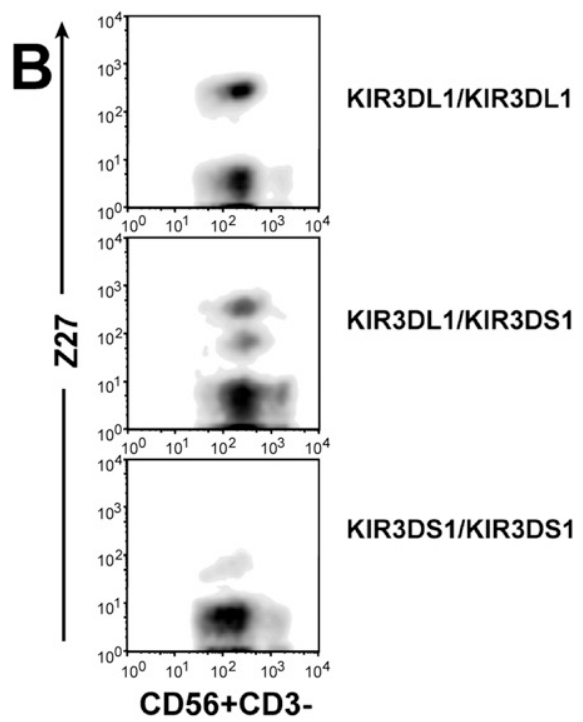

E
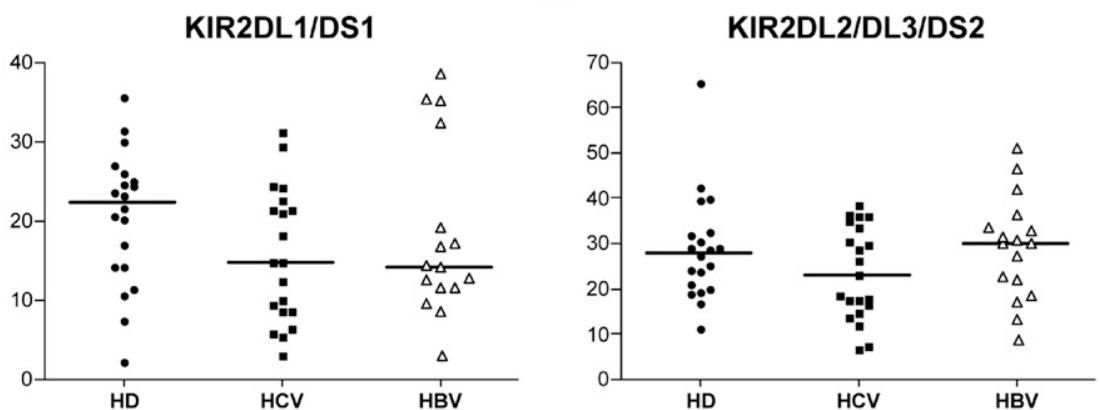

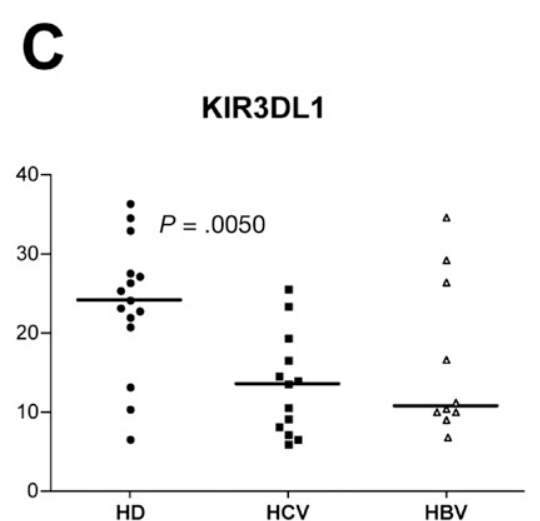

$\mathbf{F}$

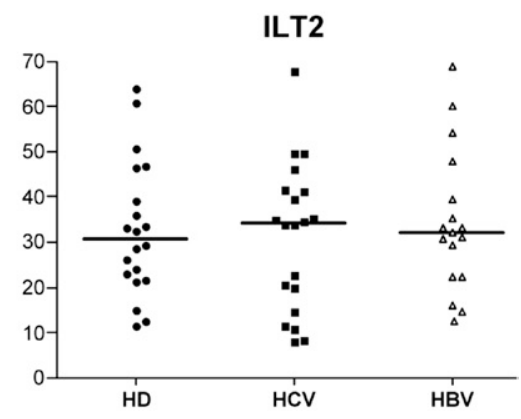

Figure 2. Single inhibitory receptor analysis shows that KIR3DL1 is significantly less expressed on NK cells from HCV-positive patients. Panels $A$ and $C$ and $D-F$ show cumulative data from all patients tested for the specific molecules indicated in the panels; the vertical axis represents the percentage of positive cells. Panel B reports differential expression of the KIR3DL1 and KIR3DS1 alleles using mAb Z27 on three representative patients: one KIR3DL1 homozygote (top), one KIR3DL1/DS1 heterozygote (middle), and one KIR3DS1 homozygote (bottom). KIR3DL1 alleleexpressing NK cells appear as the bright fraction, and KIR3DS1 allele-expressing NK cells appear as the dim fraction at flow cytometry with mAb Z27.

receptors did not differ from healthy donors (Figure $2 D-F)$.

NKR expression on the CD56 $6^{\mathrm{dim}} \mathrm{NK}$ cell subset broadly mirrored the differences between groups observed with the total NK cell population (Supplementary Figure 6A$E)$. However, when the CD56 $6^{\text {bright }}$ subset was considered for analysis, a statistically significant difference was only observed in the proportion of NKG2D ${ }^{+}$cells, which, similarly to $\mathrm{CD} 56^{\mathrm{dim}}$, was lower in $\mathrm{HBV}^{+}$compared with $\mathrm{HCV}^{+}$patients and in the proportion of NK cells expressing inhibitory receptors (data not shown).

\section{NK Cytolytic Activity in Patients With Chronic HBV and HCV Infections}

No statistically significant differences in the CD107a degranulation assay were observed using K562 target cells between healthy subjects and HBV- or HCVpositive patients in the absence of cytokine stimuli (data not shown). However, following stimulation with both combinations of cytokines, significantly decreased cytotoxicity compared with healthy donors was seen in $\mathrm{HBV}^{+}$ patients only $(P=.01$ and $P=.019$, after stimulation with IL-2+IL-12 and IL-2+IL-21, respectively; Supplementary Figure 7). Spontaneous cytotoxicity for P815 target cells in the absence of cytokines or triggering antibodies was significantly higher than healthy controls in $\mathrm{HCV}^{+}$patients and to a much lesser extent in $\mathrm{HBV}^{+}$ subjects, which in both cases was restricted to the $\mathrm{CD}^{\mathrm{dim}}$ subset (Figure $3 A$ ). Stimulation with combinations of cytokines led to a statistically significant increase in cytolytic activity only in $\mathrm{HCV}^{+}$patients compared with healthy subjects who showed levels of lytic activity comparable with $\mathrm{HBV}^{+}$patients (Figure $3 B$ ). Representative original data are shown in Figure 3C. Redirected cytotoxicity experiments are shown on Figure 4. Significantly increased degranulation was observed using anti-NKG2D and anti-NKp46 mAbs in both $\mathrm{HCV}^{+}$and $\mathrm{HBV}^{+}$patients, which again was exclusively restricted to the $\mathrm{CD} 56^{\mathrm{dim}}$ subset using anti-NKG2D $\mathrm{mAb}$ (Figure $4 A$ ). In $\mathrm{HCV}^{+}$ patients increased lytic activity was extended to $\mathrm{CD} 56^{\text {bright }}$ NK cells using NKp46- and NKp30-specific mAbs, respec- 
A
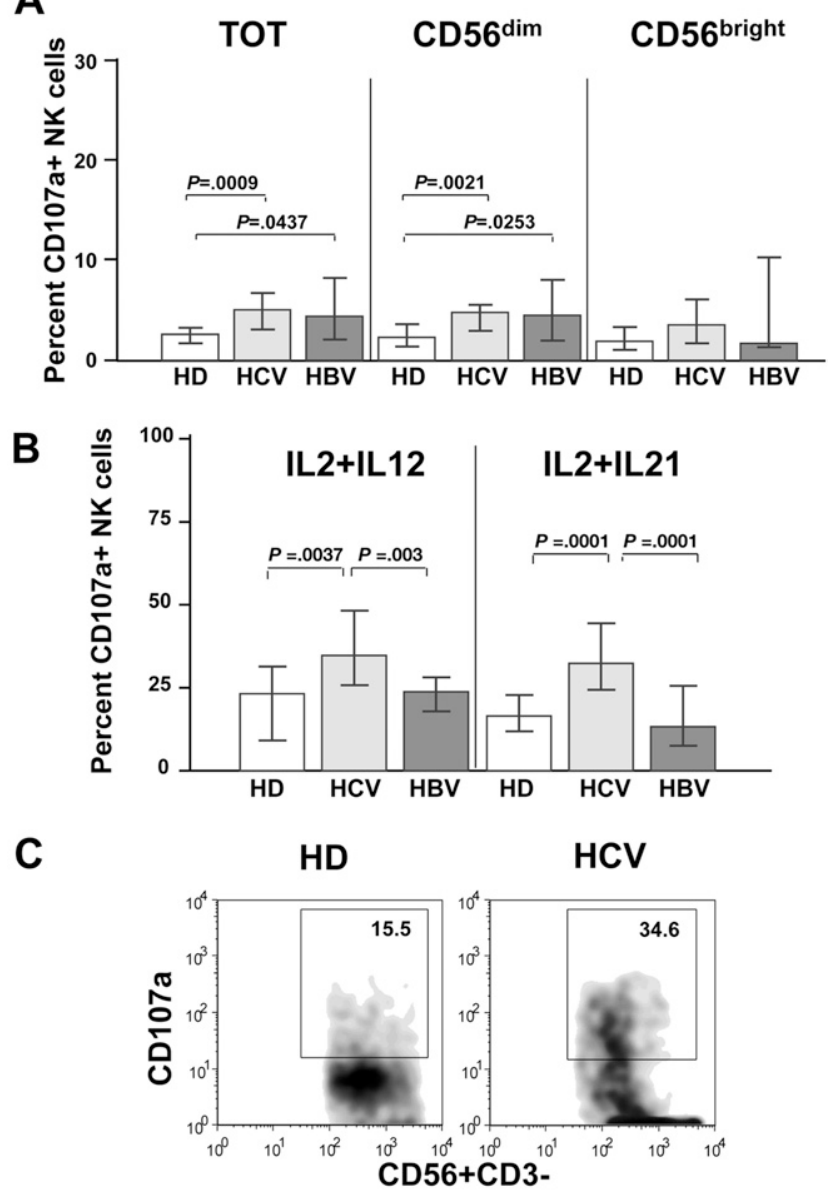

Figure 3. Spontaneous NK cytotoxicity for P815 target cells is significantly increased in patients with chronic HBV and $\mathrm{HCV}$ infections and is restricted to the CD56 dim subset $(A)$. Stimulation of NK cells with combinations of cytokines (IL-2+IL-12 or IL-2+IL-21) led to a statistically significant increase only in patients with chronic HCV infection (B). Panel $C$ shows a representative density plot of a patient with chronic HCV infection demonstrating significantly higher percentage of CD107a ${ }^{+} \mathrm{NK}$ cells compared with healthy donors following cytokine stimulation. $H D$, healthy controls (empty bars); HCV, patients with chronic HCV infection (solid light grey bars); HBV, patients with chronic HBV infection (solid dark grey bars).

tively (Figure $4 B$ and $C$ ). Cytokine stimulation with IL$2+$ IL-12 produced a nonsignificant increase in cytotoxicity in $\mathrm{HCV}^{+}$patients using NKp30 and NKp46 mAbs compared with healthy donors; however, following addition of IL-2+IL-21, the increment reached statistical significance (Figure $5 A$ and $B$ ). NCR expression was similar in all patient categories (Supplementary Figure 8), and there was no correlation between the proportion of NCRexpressing cells and redirected cytotoxicity using NCRs as triggering antibodies (not shown). Redirected cytotoxicity with anti-NKG2D mAb produced increased NK lytic activity using both cytokine combinations, which was restricted to the $\mathrm{HCV}^{+}$patient group (Figure 5C). NK lytic activity in $\mathrm{HBV}^{+}$patients was always comparable with that of healthy subjects, consistently and signifi- cantly lower than in $\mathrm{HCV}^{+}$patients (Figure $5 A-C$ ). Differential analysis of the CD56 $6^{\text {bright }}$ and CD56 dim subsets proved impossible after cytokine stimulation (not shown).

\section{NK Cell Cytokine Production in Patients With Chronic HCV and HBV Infections}

Patients with chronic HBV infection displayed significantly lower IFN- $\gamma$ and TNF- $\alpha$ production compared with healthy controls in all experimental conditions (Figure 6A-D). This was remarkably reproducible irrespective of the combination of cytokines used as stimulus and was evident in both CD56 $6^{\mathrm{dim}}$ and $\mathrm{CD} 56^{\text {bright }}$ subsets. Patients with chronic HCV infection also showed reduced cytokine production, albeit to a lower extent than $\mathrm{HBV}^{+}$patients. Indeed, IL-2+IL-12-stimulated NK

A

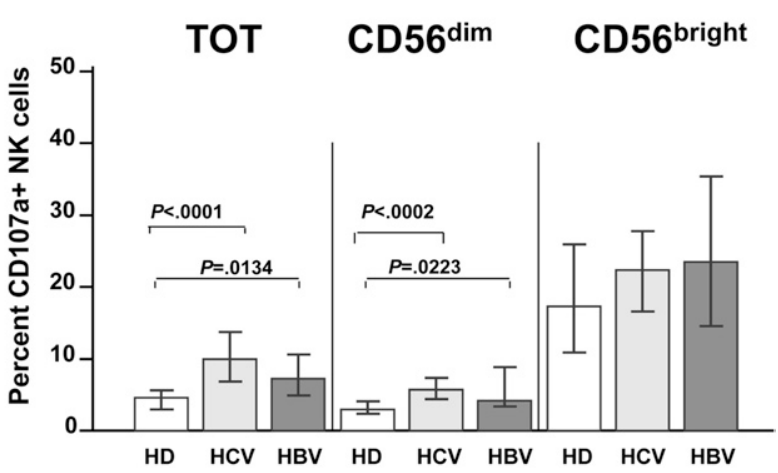

B
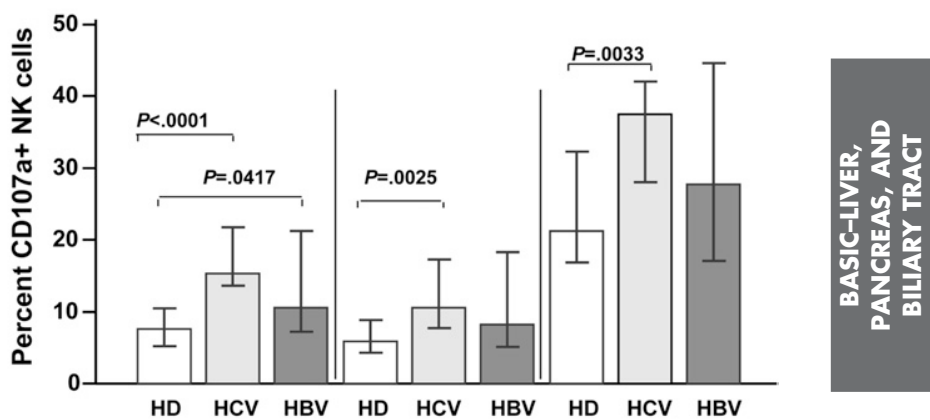

C

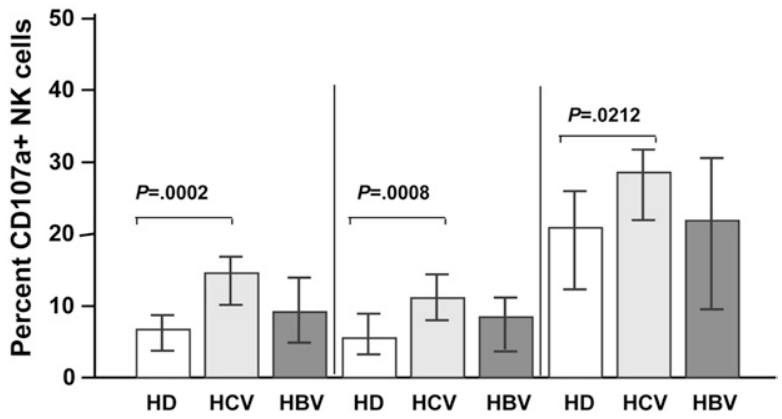

Figure 4. Redirected NK degranulation assay with P815 target cells using anti-NKG2D $(A)$, anti-NKp46 $(B)$, and anti-NKp30 $(C)$ mAbs without cytokine stimulation. $\mathrm{HD}$, healthy controls (empty bars); $\mathrm{HCV}$, patients with chronic HCV infection (solid light grey bars); HBV, patients with chronic HBV infection (solid dark grey bars). 


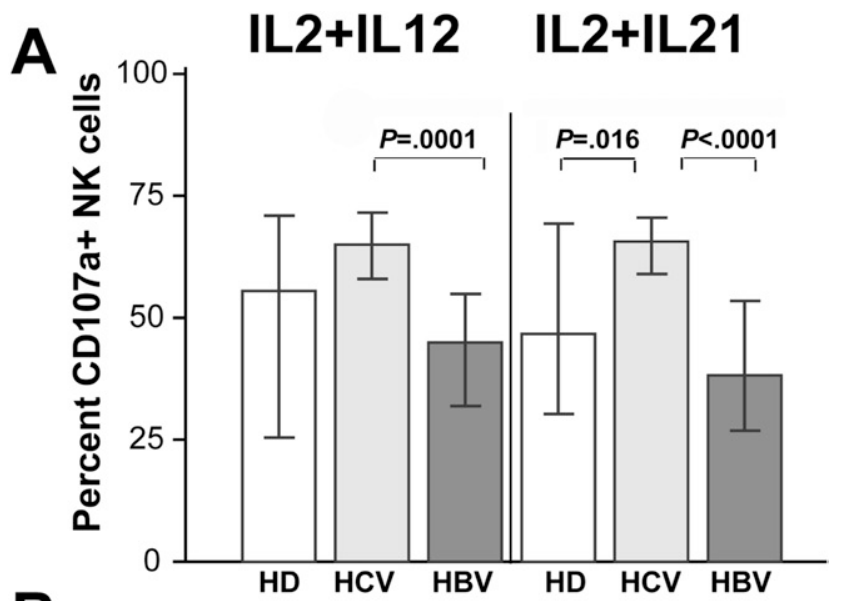

B

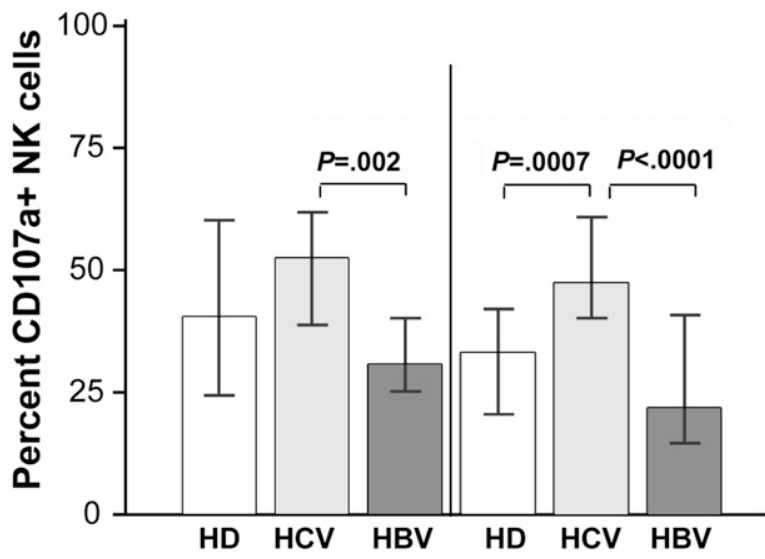

C

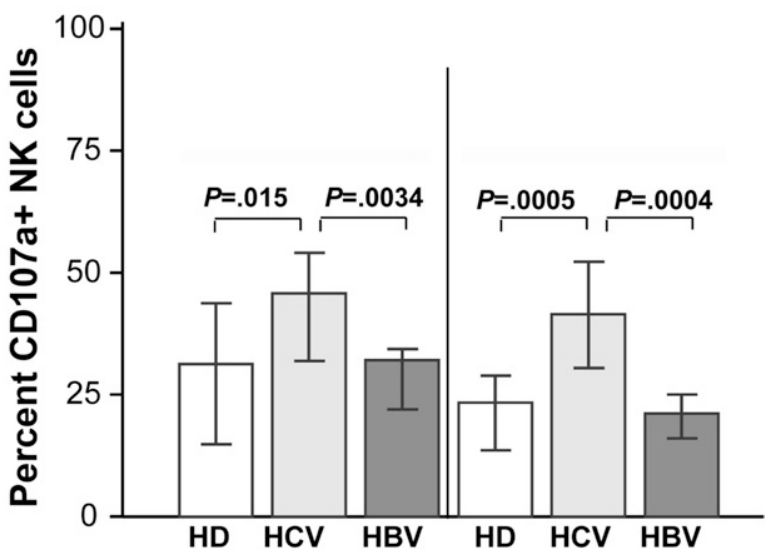

Figure 5. Redirected NK degranulation assay with P815 target cells using anti-NKp30 (A), anti-NKp46 (B), and anti-NKG2D (C) mAbs following cytokine stimulation (IL-2+IL-12 or IL-2+IL-21). Patients with chronic HBV infection display consistently lower NK cell lytic activity than patients with chronic HCV infection, who instead show significantly higher lytic activity also compared with healthy donors. $H D$, healthy controls (empty bars); HCV, patients with chronic HCV infection (solid light grey bars); HBV, patients with chronic HBV infection (solid dark grey bars).

cells induced generally lower, although not significantly diminished, cytokine production except in the CD56 bright subset in which a statistically reduced TNF- $\alpha$ production was demonstrated (Figure $6 A$ and $B$ ). However, when
IL-2+IL-21 were used as stimulus, there was a statistically significant decrease in IFN- $\gamma$ and TNF- $\alpha$ production also in $\mathrm{HCV}^{+}$patients, which was restricted to the CD56 $^{\text {dim }}$ subset (Figure $6 \mathrm{C}$ and $D$ ).

\section{Biochemical, Histologic, and Virologic Correlates of NK Phenotype and Function}

Several possible statistical correlations were sought between phenotype and function of NK cells, and biochemical (serum ALT, $\gamma$-glutamil transpeptidase, $\gamma$-globulin), or virologic (HCV genotype, serum HCV RNA or HBV DNA levels) indicators. In patients with chronic $\mathrm{HCV}$ infection, there was a statistically significant positive correlation between the proportion of activated $\left(\mathrm{CD}^{\circ} 9^{+}\right)$NK cells and serum alanine aminotransferase (ALT) as a surrogate marker of liver necroinflammation (Figure 7A), which was limited to the CD56 ${ }^{\mathrm{dim}}$ subset (Pearson, $r=0.43 ; P=.02$ ). Also, there was a positive correlation between activated NK cells and serum HCV RNA values (Figure $7 B$ ), which was limited to

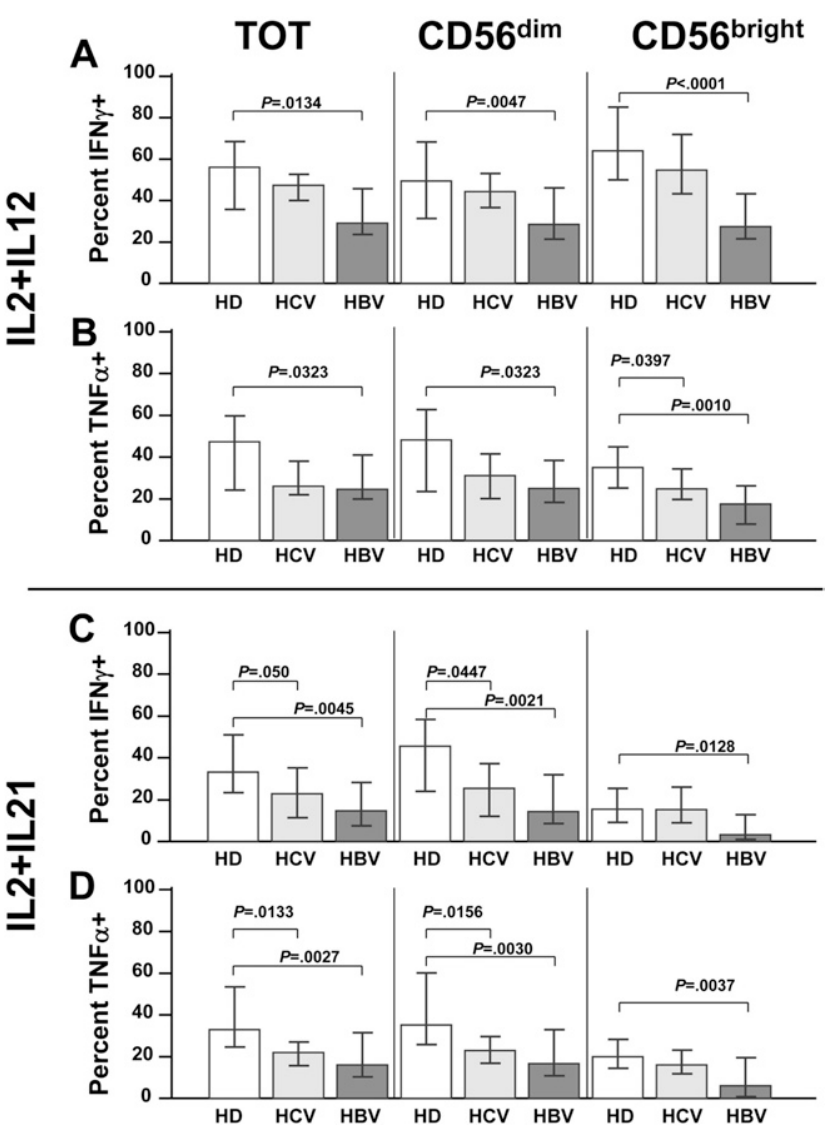

Figure 6. Production of IFN- $\gamma$ and TNF- $\alpha$ by circulating NK cells is consistently and significantly reduced in patients with chronic HBV infection and, to a lesser extent, also in patients with chronic HCV infection. Cytokine production following stimulation with IL-2+IL-12 (A,B); cytokine production following stimulation with IL-2+IL-21 $(C, D)$. HD, healthy controls (empty bars); HCV, patients with chronic HCV infection (solid light grey bars); HBV, patients with chronic HBV infection (solid dark grey bars). 
A

B
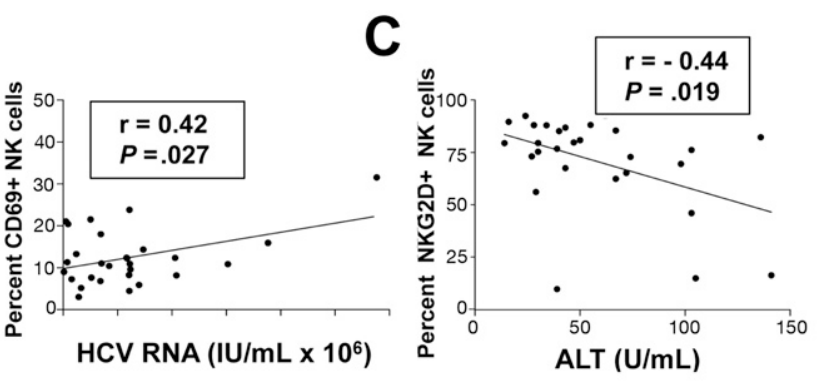

D
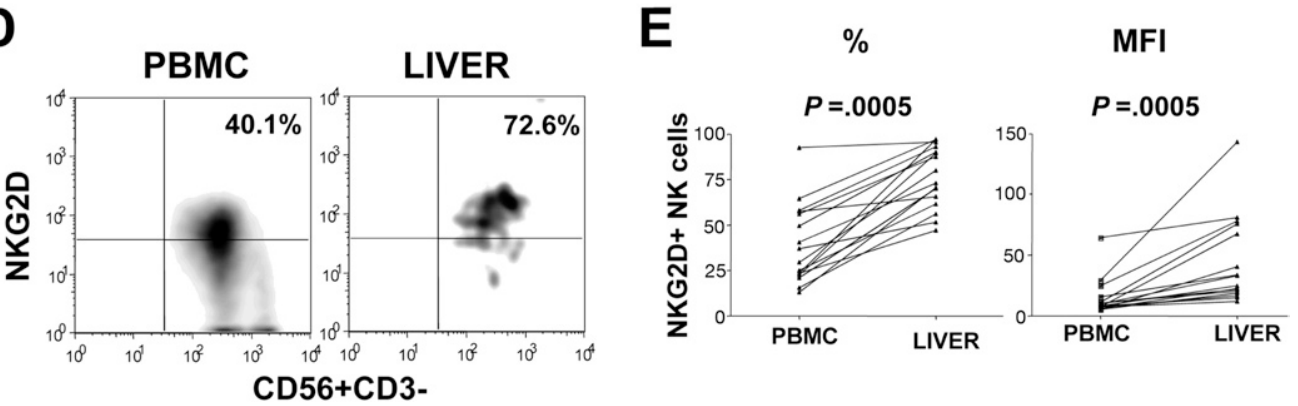

Figure 7. The proportion of activated $\left(\mathrm{CD}^{2} 9^{+}\right)$NK cells positively correlates with serum ALT (panel $A$ ) and HCV RNA (panel B) levels in patients with chronic HCV infection. Panel $C$ shows a negative correlation between NKG2D ${ }^{+}$NK cells and ALT. Results are expressed as Pearson correlation coefficients. Panel $D$ illustrates a representative density plot in a $\mathrm{HCV}^{+}$patient showing proportions of NKG2D+ $\mathrm{NK}$ cells from the peripheral blood and the intrahepatic compartments, respectively. Panel $E$ shows the proportions of NKG2D ${ }^{+} \mathrm{NK}$ cells and the corresponding NKG2D mean fluorescence intensity in the peripheral blood and liver from 16 patients with chronic HCV infection. In this experiment, a small fragment of a diagnostic liver biopsy specimen was mechanically disrupted and digested with collagenase IV and DNAse. Viable intrahepatic mononuclear cells were analysed by flow cytometry as described. ${ }^{21}$

the CD56 bright subset (Pearson, $r=0.56 ; P=.003$ ). Interestingly, there was a statistically significant negative correlation between the proportion of $\mathrm{NKG}_{2} \mathrm{D}^{+} \mathrm{NK}$ cells and ALT (Figure 7C). This NK subset appeared to concentrate in the liver as shown by findings indicating a substantial enrichment of NKG2D-positive cells in the intrahepatic compartment compared with the peripheral blood (Figure $7 D$ and $E$ ). There was a positive correlation between frequencies of circulating and intrahepatic NKG2D-positive NK cells (Pearson, $r=0.51, P=.04$ ). However, no direct correlation was found between total populations of peripheral and intrahepatic NK cells (not shown). No relevant statistical correlations were found with functional data, eg, CD107a degranulation and cytokine intracellular staining (not shown). Moreover, no correlations were found in patients with chronic HBV infection between NK phenotype and function and the indicators listed above (not shown).

\section{Discussion}

NK cells are tightly regulated by signals through a variety of stimulatory, costimulatory, and inhibitory receptors, which bind components of pathogens, host cells, or cytokines. ${ }^{8-10}$ In this study, we analyzed the expression of a large number of NK inhibitory and activating receptors and showed that there exist profound differences in NK cell phenotype and function between chronic HBV and HCV infections. In the latter, there was an increased proportion of NKG2D-expressing NK cells, which was also supported by mean fluorescence intensity data, and a concomitant decrease in those expressing inhibitory receptors, supporting the concept of a phenotype skewed toward activation, predominantly involving the NKG2D pathway. Instead, in the former, there was an increased proportion of NKG2C-expressing cells with normal inhibitory receptor expression, suggesting a more balanced activating/inhibitory receptor expression. Although single inhibitory receptor expression analysis clearly showed significantly decreased proportions of KIR3DL1/DS1expressing NK cells in both HCV- and HBV-infected patients, reduction of the inhibitory KIR3DL1 alleleexpressing cells was only seen in HCV-positive patients, which identifies KIR3DL1/DS1 as a major candidate receptor involved in NK regulation in chronic HCV infection. Interestingly, KIR3DL1 has a long cytoplasmic tail that permits inhibitory signalling, whereas KIR3DS1 lacks the immunoreceptor tyrosine-based inhibition motif as other activating receptors and effectively functions as an activating receptor. ${ }^{30,31}$ KIR3DL1- and KIR3DS1expressing cells can be easily identified as they segregate as different subsets of $\mathrm{mAb}$ Z27 $7^{\text {bright }}$ and $\mathrm{Z} 27^{\mathrm{dim}}$ cells, respectively. ${ }^{31}$ Expression of KIR3DS1 has been associated with delayed progression to AIDS and opportunistic infections, ${ }^{32,33}$ lending further support to the notion that it acts as activating receptor. Whether similar regulatory mechanisms are implicated in the progression of chronic hepatitis $\mathrm{C}$ requires further studies. 
Differences in NKR expression were mirrored by clear functional differences. Whereas reduced NK cell frequencies did not affect spontaneous cytolytic effector function in agreement with previous studies, ${ }^{12,13,34,35} \mathrm{NK}$ cells from $\mathrm{HCV}^{+}$patients responded well to cytokine stimulation displaying normal or increased cytolytic activity towards K562 and P815 target cells, respectively, at variance with data suggesting that HCV envelope proteins impair NK cell activation and function ${ }^{14,15}$ and consistent with recently published findings indicating that culture-derived infectious HCV particles do not affect NK function. ${ }^{36}$ This was further confirmed in the redirected cytotoxicity assay, which clearly showed that HCV infection is able to enhance NK cytotoxicity mainly through the NKG2D pathway and that NCRs, such as NKp30 and NKp46, are also involved despite apparently not being expressed at levels higher than healthy donors. Instead, patients with chronic HBV infection displayed normal or even lower cytotoxic activity for P815 and K562 targets, respectively, upon cytokine stimulation compared with patients with chronic HCV infection and healthy subjects, and, in keeping with this observation, redirected killing was indistinguishable from healthy donors. In this respect, our findings disagree with studies that showed deficient NK cytolytic activity in HCV-infected subjects $^{14-19}$ but are in agreement with several others showing conserved cytotoxic potential. ${ }^{12,13,34,35}$ The reasons for such discrepancies are not immediately apparent, although they may be due, in part, to clinical, biochemical, and virologic heterogeneity of patients, for which we have attempted to control by performing an extended phenotypic and functional analysis in a substantial number of unselected patients and healthy donors.

The CD69 early activation antigen ${ }^{37}$ was expressed in a higher proportion of NK cells from $\mathrm{HCV}^{+}$patients compared with $\mathrm{HBV}^{+}$patients, possibly explaining differences in the effector cytotoxic potential observed in the 2 patient groups. Interestingly, in $\mathrm{HCV}^{+}$patients, the proportion of $\mathrm{CD} 69^{+} / \mathrm{CD} 56^{\mathrm{dim}} \mathrm{NK}$ cells correlated with serum ALT, a surrogate marker of liver necroinflammation, suggesting that mature activated NK cells are involved in liver immunopathology in this setting. Moreover, the direct correlation between serum HCV RNA levels and CD69 ${ }^{+}$NK (CD56 bright) cells would be compatible with the observation that HCV replication is responsible for activation of this NK cell subset during chronic infection as shown by others, ${ }^{13}$ although we were unable to confirm the reported increase in IFN- $\gamma$ production by these cells.

The frequencies and phenotype of the CD56 $6^{\mathrm{dim}} \mathrm{NK}$ cells and their degranulation capacity in the absence of cytokine stimuli broadly reflected the results obtained with the total NK cell population and emphasized their propensity toward cytolytic function, ${ }^{8-10}$ although, in HCV-infected patients, significant redirected cytotoxicity could be documented also in the CD56 $6^{\text {bright }}$ subset. How- ever, stimulation with cytokines conferred IFN- $\gamma$ and TNF- $\alpha$ production ability to both subsets, suggesting that the broadly accepted functional differences between the 2 subsets may not be so rigid, at least in this in vitro system.

The finding of a negative correlation between circulating NKG2 $\mathrm{D}^{+} \mathrm{NK}$ cells and ALT in patients with chronic HCV suggests homing of these cells to the liver where they may exert effector cytotoxic function, as supported by our preliminary findings demonstrating that $\mathrm{NKG}_{2} \mathrm{D}^{+} \mathrm{NK}$ cells are highly enriched in the intrahepatic compartment. NKG2D belongs to the II C-type lectinlike family of transmembrane proteins and functions both as an activating and costimulatory receptor serving a fundamental role in the surveillance against microbial infections and cancer. ${ }^{38,39}$ The natural ligands for NKG2D are major histocompatibility complex class I chain-related proteins A and B (MICA and -B), which are stress inducible, nonclassical class I molecules, both of which can activate NK cells, ${ }^{40}$ and members of the retinoic acid early inducible RAE-1 protein family, some of which were initially characterized as ligands for the CMV UL16 protein. ${ }^{41}$ Interestingly, interaction of NKG2D with RAE-1 on hepatocytes in a transgenic mouse model of HBV infection was found to be an important recognition pathway of experimental NK cell-mediated liver injury. ${ }^{42}$ However, expression of NKG2D ligands in the healthy and diseased human liver is only partially known in the case of $\mathrm{MICA}^{43}$ and notably lacking in the case of RAE-1. Studies addressing this issue are currently in progress in our laboratory.

While differences in the cytotoxic potential between $\mathrm{HBV}^{+}$and $\mathrm{HCV}^{+}$patients were robust and reproducible, IFN- $\gamma$ and TNF- $\alpha$ production following stimulation with different cytokine combinations was shown to be dysfunctional also in $\mathrm{HCV}^{+}$patients, even though to a lesser extent than in $\mathrm{HBV}^{+}$patients. Different cytokine combinations seemed to account for different responses. Indeed, the presence of IL-21 proved to be a weaker stimulus in combination with IL-2 compared with IL- $2+$ IL-12, which maintained IFN- $\gamma$ and TNF- $\alpha$ production at a lower, although statistically comparable, level than that of healthy donors.

Collectively, our data provide evidence for a functional dichotomy in chronic HCV infection, with a clearly enhanced basal and cytokine-induced lytic activity and a reduced TNF- $\alpha$ and IFN- $\gamma$ production, a functional defect that was definitely more profound in the setting of chronic HBV infection. The biologic consequences of dysfunctional cytokine production in chronic hepatitis $\mathrm{C}$ would be that HCV persists in the host in the face of an enhanced NK cytotoxic activity. Indeed, IFN- $\gamma$ production has been shown to be a powerful non-cytolytic mechanism of viral clearance from infected hepatocytes, ${ }^{44}$ and it can specifically inhibit HCV replication in vitro. ${ }^{45,46}$ Interestingly, IFN- $\gamma$ production by virus-spe- 
cific $\mathrm{T}$ cells is also significantly impaired during chronic $\mathrm{HCV}$ infection, ${ }^{47,48}$ adding to the concomitant NK cell defect we have demonstrated here. TNF- $\alpha$, instead, appears to be inefficient in controlling HCV replication as shown in replicon-containing hepatoma cells compared with IFN- $\gamma,{ }^{49}$ but it seems to be a key mediator in HBV persistence because of its direct antiviral effect ${ }^{44}$ and because it is essential for the proliferation of HBV-specific cytotoxic T cells. ${ }^{50}$ Moreover, patients treated with TNF- $\alpha$ inhibitors may incur a severe reactivation of chronic hepatitis $\mathrm{B}$, adding further evidence in support of the importance of this cytokine in HBV control. ${ }^{51}$ The markedly defective NK cytokine production in the context of a relatively normal or reduced (in the case of K562 target cells) NK cytolytic activity only in HBV infection presumably reflects the poor cellular response to type I IFN-inducible genes in this condition ${ }^{1}$ and suggests that the previously reported mechanism of cytokine-induced tumor necrosis factor-related apoptosis-inducing ligand (TRAIL)-mediated NK cell killing of hepatocytes probably occurs predominantly during liver inflammatory flares, ${ }^{52}$ which are typically observed in this setting. ${ }^{53}$

In conclusion, our study revealed previously unappreciated findings in patients with chronic HBV and HCV infections, featuring conserved or enhanced cytolytic activity and dysfunctional cytokine production, which may be a key factor contributing to virus persistence and chronic liver immunopathology.

\section{Supplementary Data}

Note: To access the supplementary material accompanying this article, visit the online version of Gastroenterology at www.gastrojournal.org, and at doi: $10.1053 /$ j.gastro.2009.05.047.

\section{References}

1. Wieland SF, Chisari FV. Stealth and cunning: hepatitis B and hepatitis C viruses. J Virol 2005;79:9369-9380.

2. Cheng G, Zhong J, Chisari FV. Inhibition of dsRNA-induced signalling in hepatitis $C$ virus-infected cells by NS3 protease-dependent and -independent mechanisms. Proc Natl Acad Sci U S A 2006; 103:8499-8504.

3. Loo YM, Owen DM, Li K, et al. Viral and therapeutic control of IFN- $\beta$ promoter stimulator 1 during hepatitis $C$ virus infection. Proc Natl Acad Sci U S A 2006;103:6001-6006.

4. Foy E, Li K, Wang CY, et al. Regulation of interferon regulatory factor-3 by the hepatitis C virus serine protease. Science 2003; 300:1145-1148.

5. Johnson CL, Owen DM, Gale M. Functional and therapeutic analysis of hepatitis C virus NS3.4A protease control of antiviral immune defense. J Biol Chem 2007;282:10792-10803.

6. Kakimi K, Guidotti LG, Koezuka Y, et al. Natural killer T cell activation inhibits hepatitis $B$ virus replication in vivo. J Exp Med 2000;192:921-930.

7. Vilarinho S, Ogasawara K, Nishimura S, et al. Blockade of NKG2D on NKT cells prevents hepatitis and the acute immune response to hepatitis B virus. Proc Natl Acad Sci U S A 2007;104: 18187-18192.
8. Vivier E, Tomasello E, Baratin M, et al. Functions of natural killer cells. Nat Immunol 2008;9:503-510.

9. Caligiuri MA. Human natural killer cells. Blood 2008;112:461469.

10. Lanier LL. NK cell recognition. Annu Rev Immunol 2005;23:225274.

11. Khakoo SI, Thio CL, Martin MP, et al. HLA and NK cell inhibitory receptor genes in resolving hepatitis $C$ virus infection. Science 2004;305:872-874.

12. Morishima C, Paschal DM, Wang CC, et al. Decreased NK cell frequency in chronic hepatitis $C$ does not affect ex vivo cytolytic killing. Hepatology 2006;43:573-580.

13. Golden-Mason L, Madrigal-Estebas L, McGrath E, et al. Altered natural killer cell subset distributions in resolved and persistent hepatitis $\mathrm{C}$ virus infection following single source exposure. Gut 2008;57:1121-1128.

14. Tseng CT, Klimpel GR. Binding of hepatitis $C$ virus envelope protein E2 to CD81 inhibits natural killer cell functions. J Exp Med 2002;195:43-49.

15. Crotta S, Stilla A, Wack A, et al. Inhibition of natural killer cells through engagement of CD81 by the major hepatitis $C$ virus envelope protein. J Exp Med 2002;195:35-42.

16. Corado J, Toro F, Rivera H, et al. Impairment of natural killer (NK) cytotoxic activity in hepatitis C virus (HCV) infection. Clin Exp Immunol 1997;109:451-457.

17. Pár G, Rukavina D, Podack ER, et al. Decrease in CD3-negative$\mathrm{CD} 8 \operatorname{dim}(+)$ and $\mathrm{V} \Delta 2 / \mathrm{V} \gamma 9 \mathrm{TcR}+$ peripheral blood lymphocyte counts, low perforin expression and the impairment of natural killer cell activity is associated with chronic hepatitis $\mathrm{C}$ virus infection. J Hepatol 2002;37:514-522.

18. Meier UC, Owen RE, Taylor E, et al. Shared alterations in NK cell frequency, phenotype, and function in chronic human immunodeficiency virus and hepatitis C virus infections. J Virol 2005;79: 12365-12374.

19. Nattermann J, Feldmann G, Ahlenstiel G, et al. Surface expression and cytolytic function of natural killer cell receptors is altered in chronic hepatitis C. Gut 2006;55:869-877.

20. Szabo G, Chang S, Dolganiuc A. Altered innate immunity in chronic hepatitis C infection-cause or effect? Hepatology 2007; 46:1279-1290.

21. Varchetta S, Oliviero B, Donato MF, et al. Prospective study of natural killer cell phenotype in recurrent hepatitis $C$ virus infection after liver transplantation. J Hepatol 2009;50:314-322.

22. Pala P, Hussell T, Openshaw PJ. Flow cytometric measurement of intracellular cytokines. J Immunol Methods 2000;243:107-124.

23. Strengell M, Matikainen S, Siren J, et al. IL-21 in synergy with IL-15 and IL-18 enhances IFN- $\gamma$ production in human NK and T cells. J Immunol 2003;170:5464-5469.

24. Parrish-Novak J, Dillon SR, Nelson A, et al. Interleukin 21 and its receptor are involved in NK cell expansion and regulation of lymphocyte function. Nature 2000;408:57-63.

25. Bryceson YT, March ME, Ljunggren HG, et al. Activation, coactivation, and costimulation of resting human natural killer cells. Immunol Rev 2006;214:73-91.

26. Betts MR, Benchley JM, Price DA, et al. Sensitive and viable identification of antigen-specific CD8 $+\mathrm{T}$ cells by a flow cytometric assay for degranulation. J Immunol Methods 2003;281: 65-78.

27. Rehermann B, Naoumov NV. Immunological techniques in viral hepatitis. J Hepatol 2007;46:508-520.

28. Alter G, Malenfant J, Altfeld M. CD107a as a functional marker for the identification of natural killer cell activity. J Immunol Methods 2004;294:15-22.

29. Perez-Villar JJ, Melero I, Rodriguez A, et al. Functional ambivalence of the Kp43 (CD94) NK cell-associated surface antigen. $\mathrm{J}$ Immunol 1995;154:5779-5788. 
30. O'Connor GM, Guiran KJ, Cunningham RT, et al. Functional polymorphism of the KIR3DL1/S1 receptor on human NK cells. J Immunol 2007;178:235-241.

31. Carr WH, Rosen DB, Arase H, et al. KIR3DS1, a gene implicated in resistance to progression to AIDS, encodes a DAP12-associated receptor expressed on NK cells that triggers NK cell activation. J Immunol 2007;178:647-651.

32. Martin MP, Gao X, Lee JH, et al. Epistatic interaction between KIR3DS1 and HLA-B delays the progression to AIDS. Nat Get 2002;31:429-434.

33. Qi Y, Martin MP, Gao X, et al. KIR/HLA pleiotropism: protection against both HIV and opportunistic infections. PLoS Pathog 2006;2:e79.

34. De Maria A, Fogli M, Mazza S, et al. Increased natural cytotoxicity receptor expression and relevant IL-10 production in NK cells from chronically infected viremic HCV patients. Eur J Immunol 2007;37:445-455.

35. Duesberg U, Schneiders AM, Fliegers D, et al. Natural cytotoxicity and antibody-dependent cellular cytotoxicity (ADCC) is not impaired in patients suffering from chronic hepatitis C. J Hepatol 2001;35:650-657.

36. Yoon JC, Shiina M, Ahlenstiel G, et al. Natural killer cell function is intact after direct exposure to infectious hepatitis $C$ virions. Hepatology 2009;49:12-21.

37. Clausen J, Vergeiner B, Enk M, et al. Functional significance of the activation-associated receptors CD25 and CD69 on human NK-cells and NK-like T-cells. Immunobiology 2003;207:85-93.

38. Raulet DH. Roles of the NKG2D immunoreceptor and its ligands. Nat Rev Immunol 2003;3:781-790.

39. Burgess SJ, Maasho K, Madhan M, et al. The NKG2D receptor: immunobiology and clinical implications. Immunol Res 2008;40: 18-34.

40. Bauer S, Groh V, Wu J, et al. Activation of NK cells and T cells by NKG2D, a receptor for stress-inducible MICA. Science 1999;285: 727-729.

41. Cosman D, Mullberg J, Sutherland CL, et al. ULBPs, novel MHC class I-related molecules, bind to CMV glycoprotein UL16 and stimulate NK cytotoxicity through the NKG2D receptor. Immunity 2001;14:123-133.

42. Chen $Y$, Wei H, Sun R, et al. Increased susceptibility to liver injury in hepatitis $B$ virus transgenic mice involves NKG2D-ligand interaction and natural killer cells. Hepatology 2007;46:706-715.

43. Zhang S, Hüe S, Sène D, et al. Expression of major histocompatibility complex class I chain-related molecule A, NKG2D, and transforming growth factor- $\beta$ in the liver of humans with alveolar echinococcosis: new actors in the tolerance to parasites? J Infect Dis 2008;197:1341-1349.

44. Guidotti LG, Chisari FV. Non-cytolytic control of viral infections by the innate and adaptive immune response. Annu Rev Immunol 2001;19:65-91.

45. Liu C, Zhu H, Tu Z, et al. CD8+ T-cell interaction with HCV replicon cells: evidence for both cytokine- and cell-mediated antiviral activity. Hepatology 2003;37:1335-1342.
46. Wang $\mathrm{SH}$, Huang $\mathrm{CX}$, Ye L, et al. Natural killer cells suppress ful cycle HCV infection of human hepatocytes. J Viral Hepat 2008; 15:855-864.

47. Rehermann B, Nascimbeni M. Immunology of hepatitis B virus and hepatitis C virus infection. Nat Rev Immunol 2005;5:215229.

48. Accapezzato D, Francavilla V, Paroli M, et al. Hepatic expansion of a virus-specific regulatory CD8(+) T-cell population in chronic hepatitis C virus infection. J Clin Invest 2004;113:963-972.

49. Liu C, Zhu H, Tu Z, et al. CD8+ T-cell interaction with HCV replicon cells: evidence for both cytokine- and cell-mediated antiviral activity. Hepatology 2003;37:1335-1342.

50. Kasahara S, Ando K, Saito K, et al. Lack of tumor necrosis factor $\alpha$ induces impaired proliferation of hepatitis B virus-specific cytotoxic T lymphocytes. J Virol 2003;77:2469-2476.

51. Esteve M, Saro C, González-Huix F, et al. Chronic hepatitis B reactivation following infliximab therapy in Crohn's disease patients: need for primary prophylaxis. Gut 2004;53:1363-1365.

52. Dunn C, Brunetto MR, Reynolds G, et al. Cytokines induced during chronic hepatitis $B$ virus infection promote a pathway for NK cell-mediated liver damage. J Exp Med 2008;204:667-680.

53. Fattovich G, Bortolotti F, Donato F. Natural history of chronic hepatitis $B$ : special emphasis on disease progression and prognostic factors. J Hepatol 2008;48:335-352.

Received February 6, 2009. Accepted May 14, 2009.

Reprint requests

Address requests for reprints to: Mario U. Mondelli, MD,

Department of Infectious Diseases, Research Laboratories,

Fondazione I.R.C.C.S. Policlinico San Matteo, Via Taramelli 5, 27100 Pavia, Italy. e-mail: m.mondelli@smatteo.pv.it; mario.mondelli@ unipv.it; fax: (39) 0382526450.

\section{Conflicts of interest}

The authors disclose no conflicts.

\section{Acknowledgments}

The authors thank Prof Alessandro Moretta, Laboratory of Experimental Immunology, Department of Experimental Medicine, University of Genoa, Italy, for providing several NKR-specific mAbs. B.O. and S.V. contributed equally to this work.

\section{Funding}

Supported by Research Funds of the Italian Ministry of Health (Ricerca Corrente, Fondazione IRCCS Policlinico San Matteo); by a grant from the Italian Ministry of Education, University and Research MIUR (Progetti di Ricerca di Interesse Nazionale-PRIN); by an unrestricted research grant from Schering-Plough, Italy; by COPEV Associazione per la Prevenzione e Cura dell'Epatite Virale Beatrice Vitiello ONLUS; and by a generous donation from Mr Maurizio Traglio. 
Supplementary Table 1. Characteristics of Patients Studied

\begin{tabular}{lcr}
\hline & HCV & HBV \\
\hline Number & 35 & 22 \\
Sex: $M / F$ & $14 / 21$ & $13 / 9$ \\
Age, $y$, median (range) & $54(18-71)$ & $48(20-72)$ \\
ALT, $U / m L$, median (range) & $43(12-141)$ & $50.5(13-291)$ \\
Viral load, IU/mL, median (range) & $1.17 \times 10^{6}\left(0.015-5.77 \times 10^{6}\right)$ & $1.48 \times 10^{5}\left(17 \times 10^{1}-1.1 \times 10^{8}\right)$ \\
Viral genotype & Yes & ND \\
1 & 18 & \\
2 & 12 & 2 \\
3 & 1 & \\
4 & 2 & \\
\hline
\end{tabular}

NOTE. Serum HCV RNA levels were determined by quantitative Versant HCV RNA 3.0 bDNA assay (Bayer Diagnostics, Berkeley, CA: lower limit of detection $600 \mathrm{IU} / \mathrm{mL}$ ). Serum HBV DNA values were determined by an in-house real-time quantitative PCR using primers of the polymerase region with a lower limit of detection of $5 \mathrm{IU} / \mathrm{mL}$.

ND, not determined.

aGenotype was not performed in 2 patients with chronic HCV infection. 

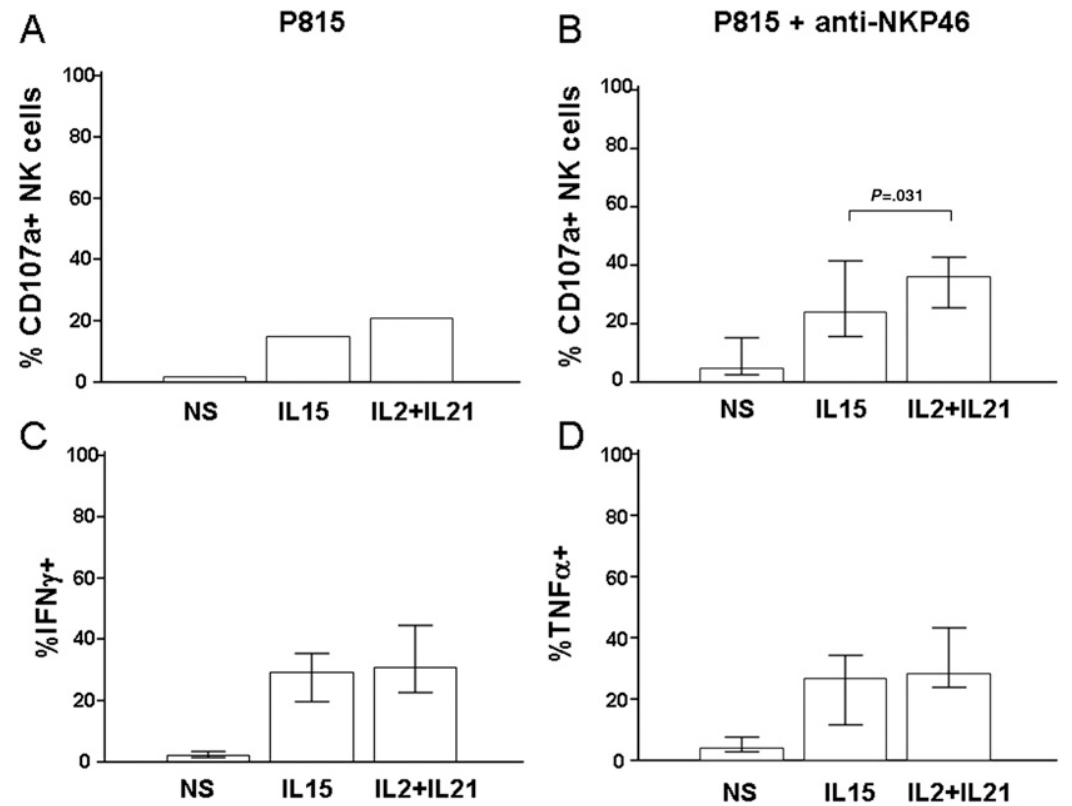

Supplementary Figure 1. Interleukin (IL)-21 is more effective than IL-15 in stimulating CD107a degranulation (A and $B)$ in a redirected cytotoxicity assay and as effective as IL-15 in cytokine production $(C$ and $D)$. Details of CD107a degranulation assay and intracellular staining are reported in Materials and Methods section. NS, data without cytokine stimulus; IL-15, data after stimulation with IL-15; IL-2+IL-21, data after stimulation with $\mathrm{IL}-2+\mathrm{IL}-21$.

UNSTIMULATED

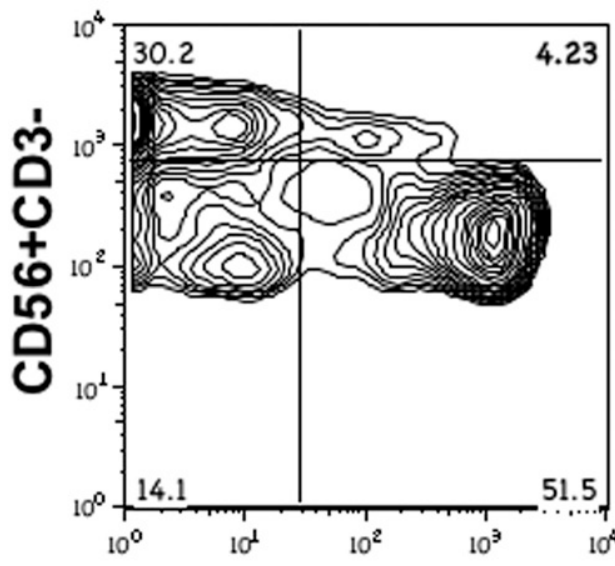

IL2+IL12

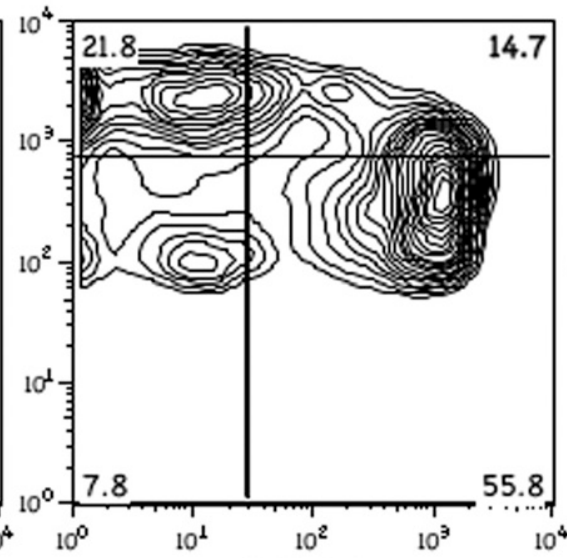

IL2+IL21

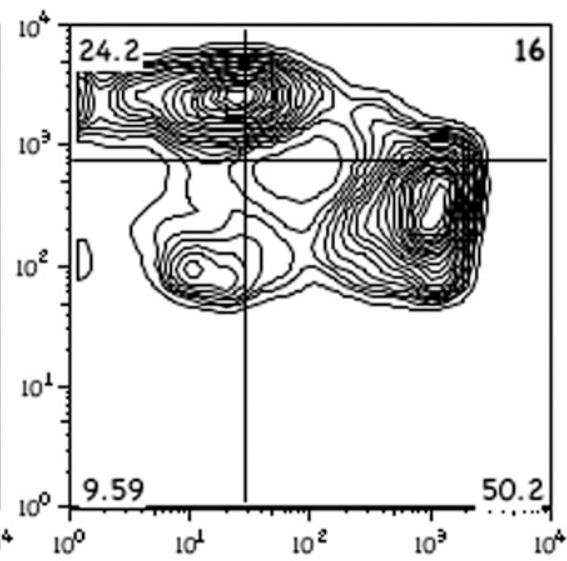

CD16

Supplementary Figure 2. Cytokine stimulation induces a 3- to 4-fold increase in CD16 expression on CD56bright natural killer (NK) cells. Expression of $\mathrm{CD} 16$ was examined on $\mathrm{CD} 6^{+} / \mathrm{CD}^{-}$cells without prior stimulation or after stimulation with the indicated cytokine combinations. Data are shown as contour plots, and percentages of gated cells are reported as appropriate. 
A

B
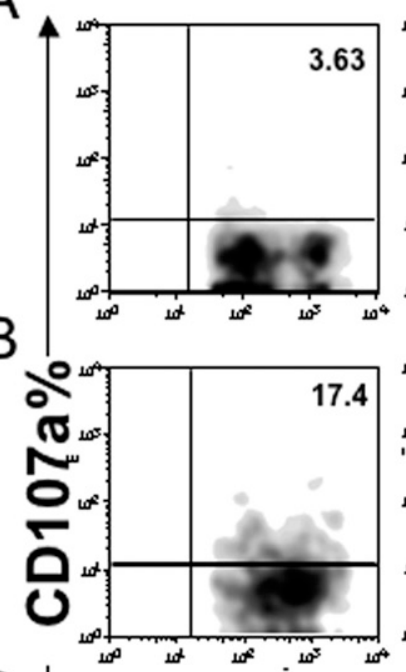

C

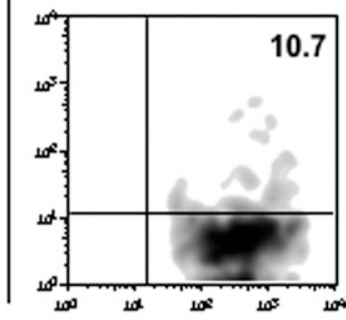

$E+T$
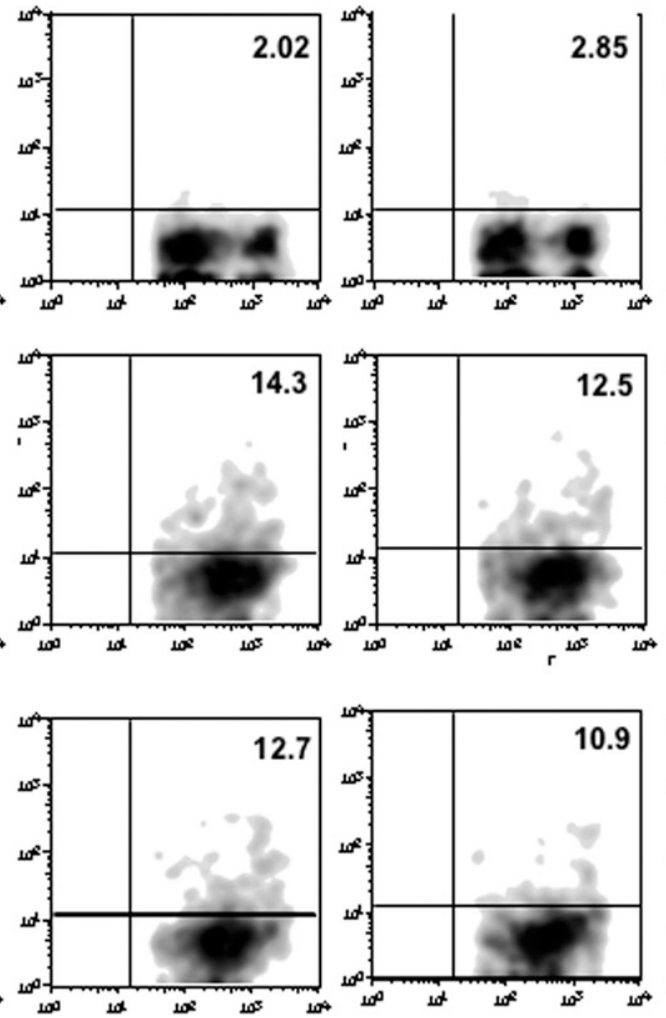

$E+T+$ control IgG

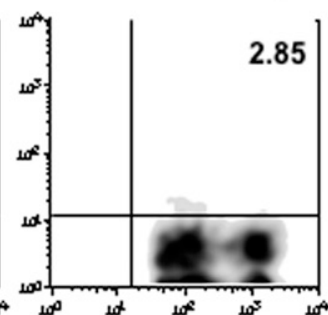

2.85

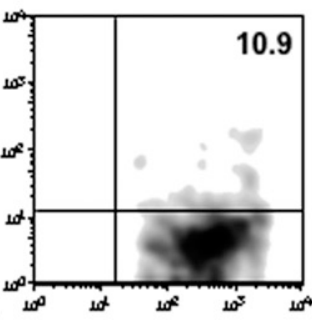

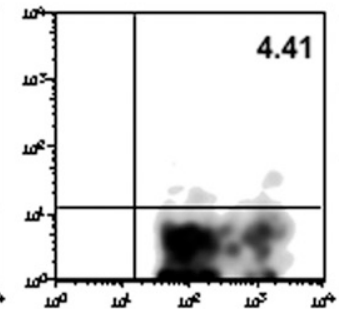
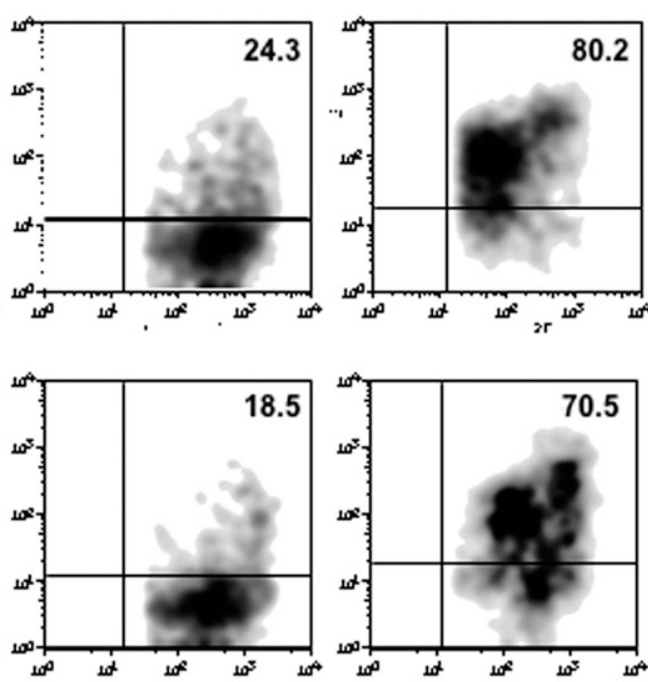

CD56+CD3-

Supplementary Figure 3. Density plots of CD107a degranulation assays reporting representative original data of a redirected cytotoxicity experiment in a patient with chronic HCV infection. Letter $A$ refers to data obtained in the absence of cytokine stimuli; letters $B$ and $C$ report data obtained after stimulation with IL-2+IL-12 and IL-2+IL-21, respectively. Target cells were P815. Experimental conditions were as listed in the Figure: Effectors alone, effector cells without target cells; $E+T$, effector cells with target cells; $E+T+$ control lgG, effector cells with target cells and isotype control; $E+T+$ anti-NKG2D, effector cells with target cells and NKG2D-specific mAb; $E+T+$ anti-NKp30, effector cells with target cells and NKp30specific mAb. Anti-NKp3O was used as positive control because it reproducibly induced strong degranulation in the redirected cytotoxicity assay. Details of the degranulation assay are reported in Materials and Methods section. 
A

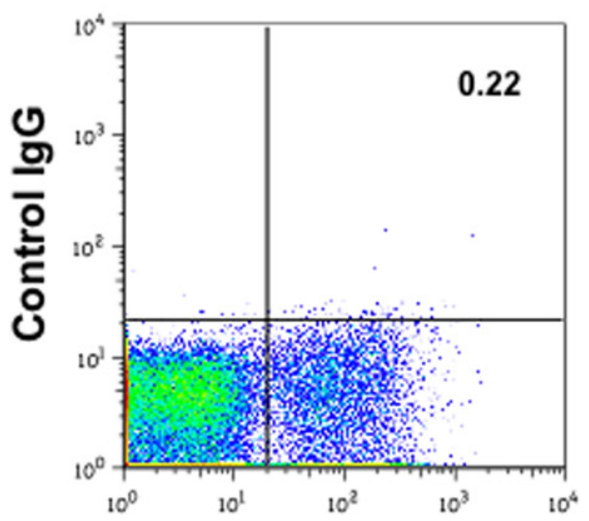

D

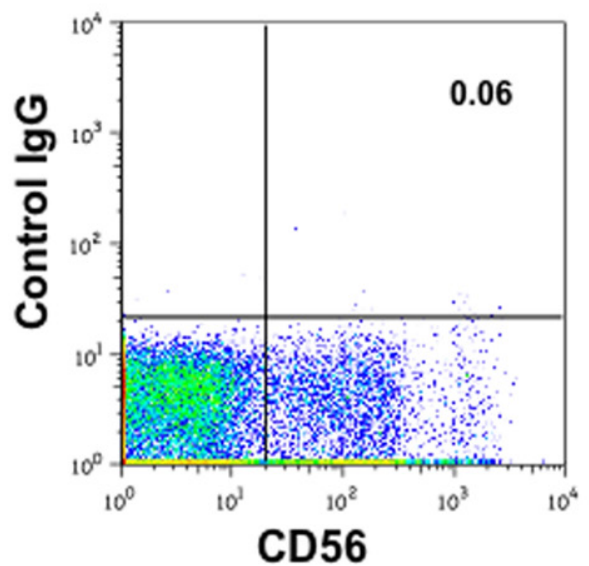

B

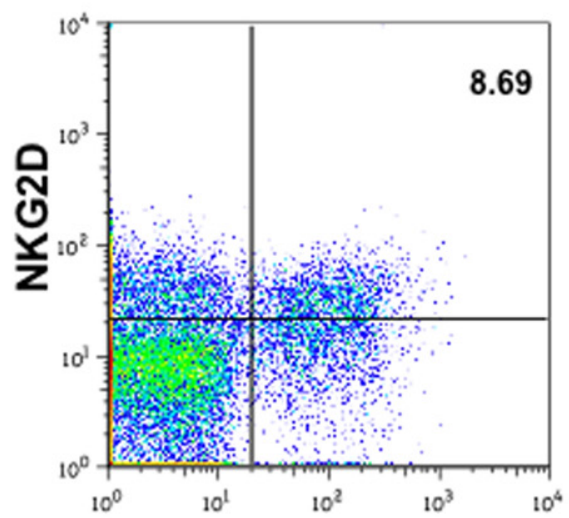

E

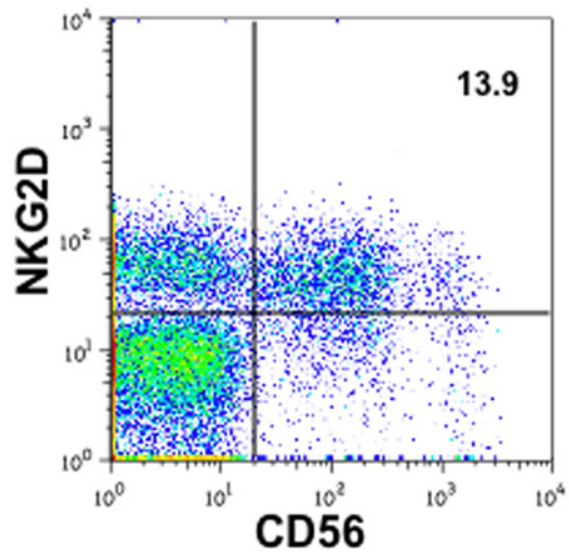

C

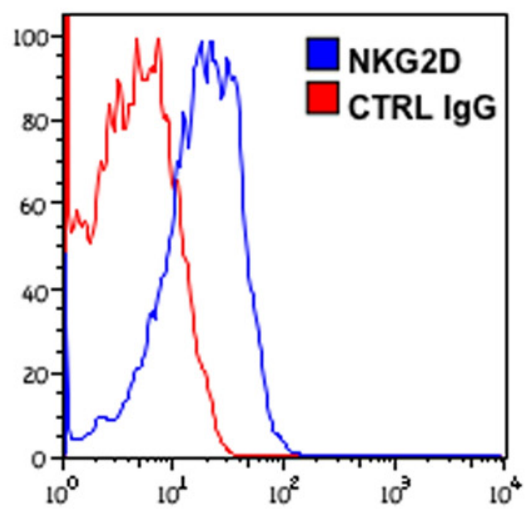

$\mathrm{F}$

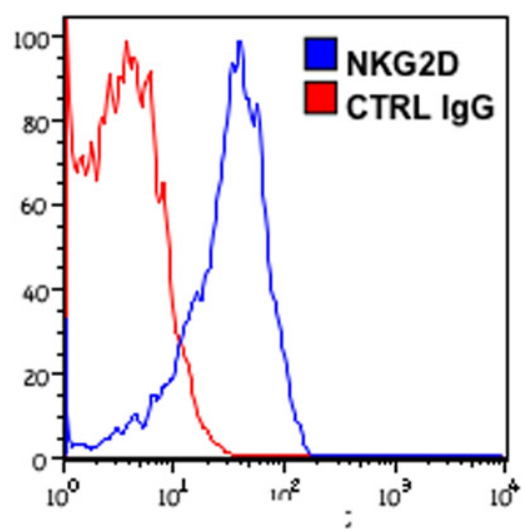

Supplementary Figure 4. Expression of NKG2D on peripheral blood NK cells from a healthy donor $(A-C)$ and an HCV-positive patient $(D-F)$. Data are shown as pseudocolor dot plots (with the percentages of gated NK cells) and histograms using an lgG isotype control and an NKG2D-specific $\mathrm{mAb}$ as reported in Materials and Methods section. 

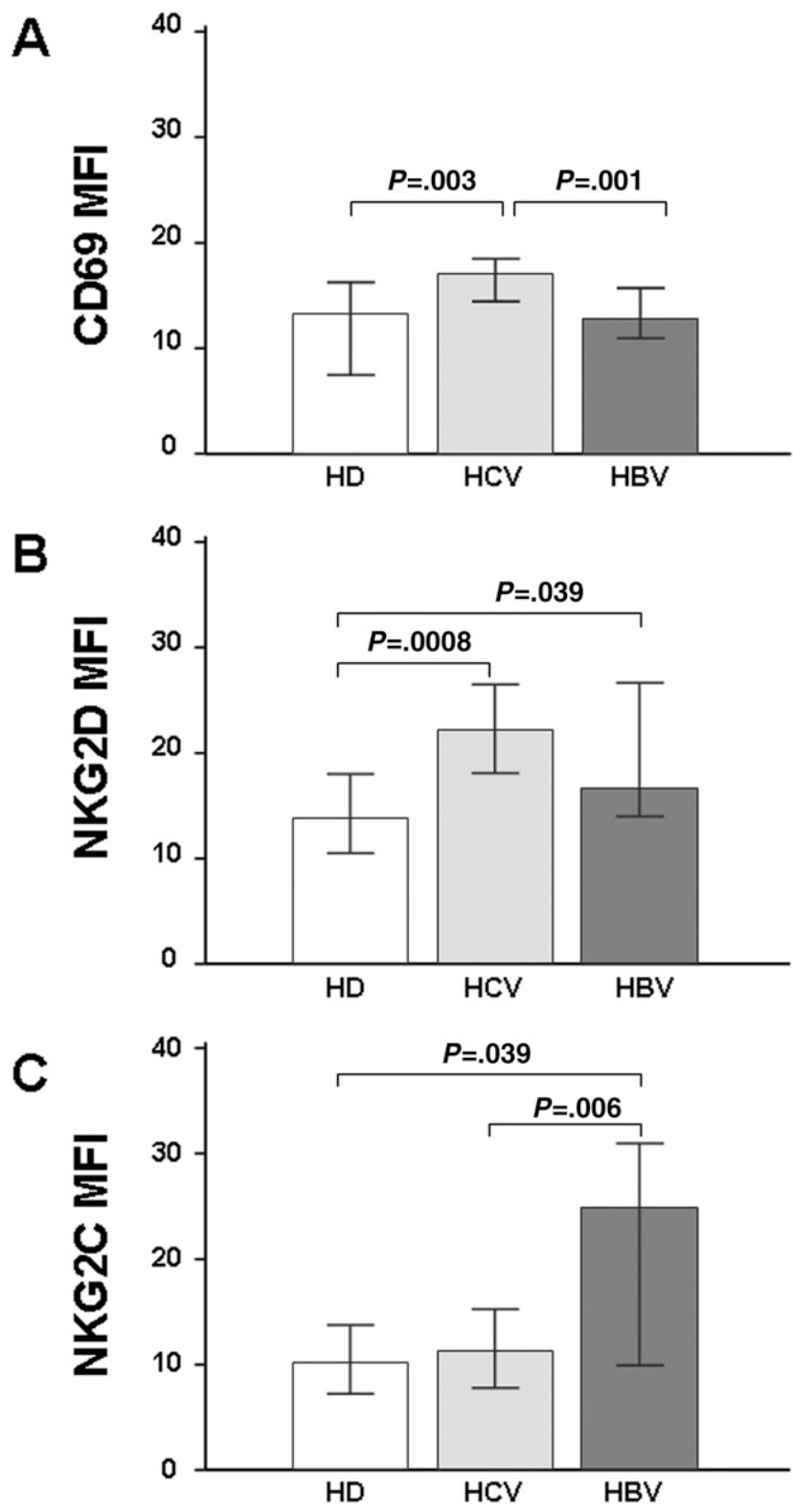

Supplementary Figure 5. Mean fluorescence intensity (MFI) of NK cell activation markers mirrors data on percentage of NK cells expressing these molecules. A, CD69; B, NKG2D; C, NKG2C. HD, healthy controls (empty bars); HCV, patients with chronic HCV infection (solid light grey bars); HBV, patients with chronic HBV infection (hatched bars). 

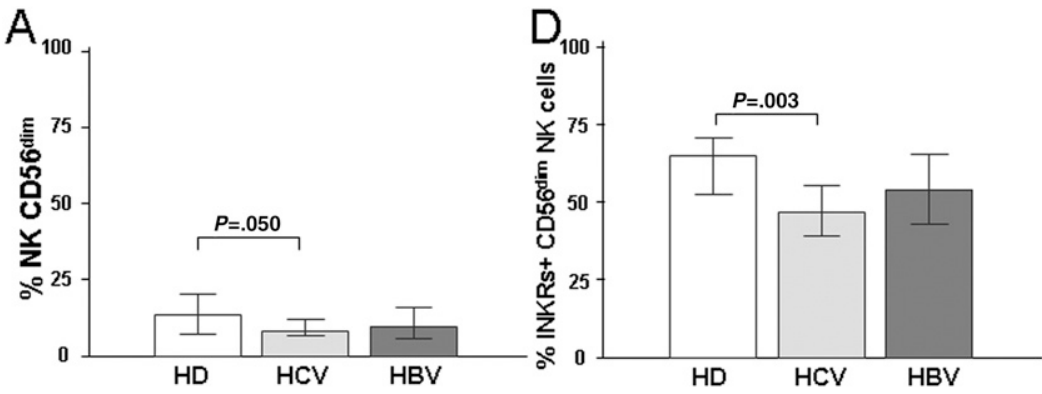

B

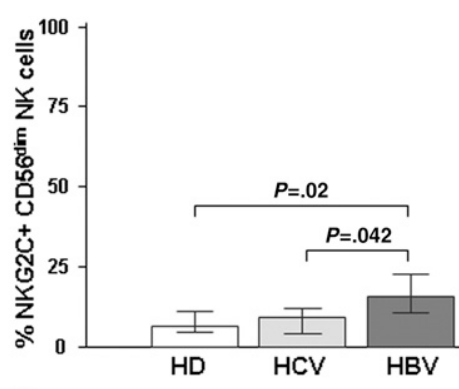

C

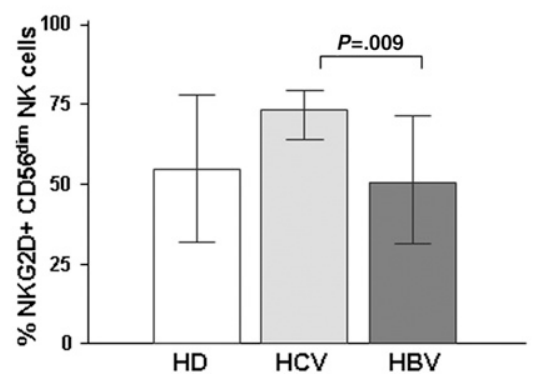

$\mathrm{E}$

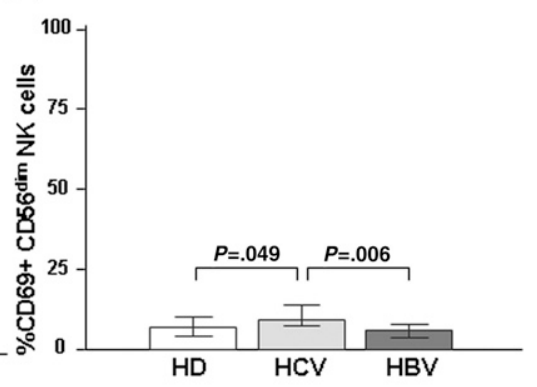

Supplementary Figure 6. Frequencies and phenotype of circulating CD56 dim NK cells in patients with chronic HBV and HCV infections. Frequencies of peripheral blood NK cells are significantly reduced in $\mathrm{HCV}^{+}$patients compared with healthy donors $(A)$. Increased proportion of $\mathrm{NKG}_{2} \mathrm{C}^{+} \mathrm{NK}$ cells in $\mathrm{HBV}^{+}$patients $(B)$ and of $\mathrm{NKG}^{+} \mathrm{D}^{+} \mathrm{NK}$ cells in $\mathrm{HCV}^{+}$patients but only when compared with $\mathrm{HBV}^{+}$patients $(C)$, which is associated with a reduced proportion of NK cells expressing inhibitory receptors (INKRs) (D) identified by a pool of mAbs, as described in Materials and Methods section. The proportion of activated $\left(\mathrm{CD} 9^{+}\right) \mathrm{NK}$ cells is significantly higher in $\mathrm{HCV}^{+}$patients compared with healthy donors and $\mathrm{HBV}+$ patients $(E)$. HD, healthy controls (empty bars); HCV, patients with chronic HCV infection (solid light grey bars); HBV, patients with chronic HBV infection (hatched bars). 


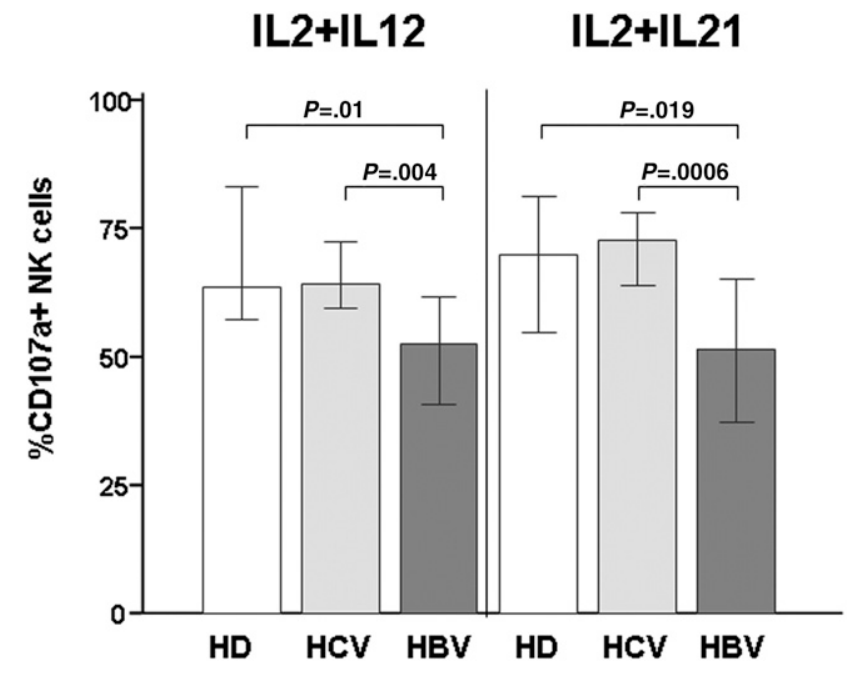

Supplementary Figure 7. Cytokine-induced NK cytolytic activity for K562 target cells is significantly reduced in patients with chronic HBV infection. PBMC were stimulated with combinations of cytokines (IL$2+\mathrm{IL}-12$ or IL-2+IL-21), and cytotoxicity was examined by the CD107a degranulation assay.
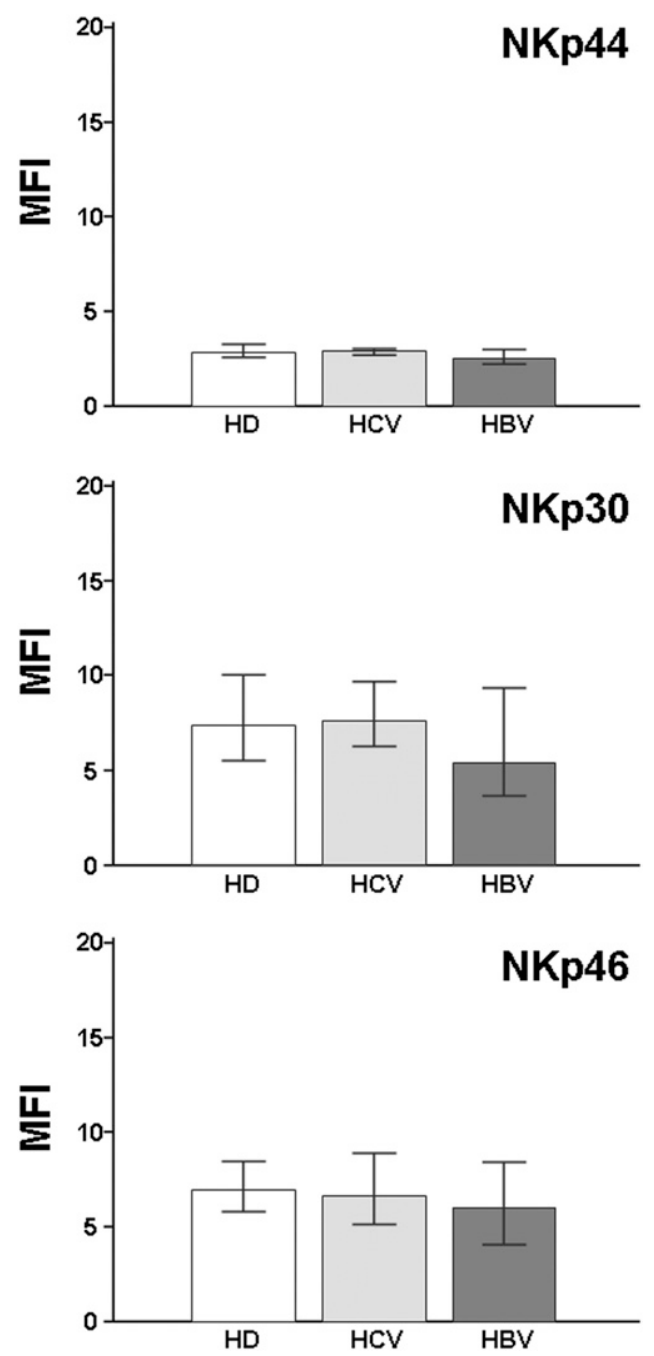

Supplementary Figure 8. Natural cytotoxicity receptors (NCRs) are expressed at equal intensity on NK cells from all subject categories. NKp30, NKp44, and NKp46 were stained on PBMC with monoclonal antibodies as described in Materials and Methods section and analyzed by flow cytometry. Data are expressed as mean fluorescence intensity (MFI). 